\title{
Las mujeres rurales en Argentina. Análisis de datos censales
}

Cristina Biaggi ${ }^{1}$ y Mónica Knopoff ${ }^{2}$

\section{RESUMEN}

La población rural en Argentina es solo un 8,9\% (CNA 2010). Hay más varones que mujeres (45\%) porque en el proceso de dejar el campo, han sido las mujeres quienes lo han hecho en mayor proporción. La migración femenina está vinculada con la disminución de la cantidad de explotaciones agropecuarias de los últimos 30 años y la situación de desventaja en la que se encuentran las mujeres, especialmente las más pobres. Las mujeres tienen más dificultades para conseguir empleo en las áreas rurales, incluso con mayor nivel educativo que los varones. La división del trabajo en los hogares sigue siendo rígida; las mujeres continúan siendo las principales responsables de la seguridad alimentaria y son las que enfrentan las dificultades de acceso a los servicios de salud. Finalmente, hay un subregistro del trabajo de las mujeres rurales en los censos de población y es necesario modificar las preguntas para abarcar mejor las cuestiones de género.

Palabras claves mujeres rurales; migración femenina; subregistro trabajo femenino; nivel educativo.

\section{ABSTRACT}

The rural population in Argentina is only 8.9\% (CNA 2010). There are more men than women $(45 \%)$ due to a greater proportion in migration from the rural areas. Female migration is linked to the decrease in the total number of farms in the last 30 years and the disadvantaged situation of women, especially the poorest ones. For women is more difficult to find a job in rural areas, even with a higher level of education than men. The division of labor in rural households remains rigid; women continue to be the main responsible for food security and they face difficulties in accessing health services. Finally, women's work is underreported in rural in population census. It is necessary to modify the census' questionary to better cover gender issues.

Keywords: rural women; female migration; underreported female work; education level.

\footnotetext{
1 INTA (Instituto Nacional de Tecnología Agropecuaria) - TRAMA (Red de Mujeres y Organizaciones que trabajan con Mujeres Indígenas y Campesinas argentinas). Contacto: biaggi.maria@inta.gob.ar

2 SAFCl (Secretaría de Agricultura Familiar, Campesina e Indígena) - TRAMA (Red de Mujeres y Organizaciones que trabajan con Mujeres Indígenas y Campesinas argentinas). Contacto: mknopoff@magyp.gob.ar
} 


\section{INTRODUCCION}

El objetivo de esta presentación es analizar la información del Censo Nacional de Población 2010, puesta a disposición por el Instituto Nacional de Estadísticas y Censos (INDEC) con la intención de conocer a la población rural de Argentina, con énfasis en las mujeres, desde una perspectiva cuantitativa. El esfuerzo de este trabajo está puesto en analizar las variables que visibilizan las diferencias entre varones y mujeres, tomando a las relaciones de género como un indicador potente y privilegiado de las desigualdades existentes en las sociedades (Ferro, 2013) ${ }^{3}$.

Aunque la información principal proviene del CNPyV 2010, en los diferentes apartados se realizan comparaciones con datos del año 2001 y otros censos de población, además de menciones acotadas del Censo Nacional Agropecuario 2018. El primer insumo para este análisis comparativo histórico es el libro Mujeres que trabajan la tierra del año 2007 y los estudios previos realizados por la Secretaría de Agricultura, Ganadería y Pesca y el PROINDER ${ }^{4}$ (1994; 2002; 2006). También se consideró en varios apartados el trabajo exhaustivo de la publicación Las nuevas generaciones de mujeres rurales como promotoras del cambio (2015), teniendo en cuenta en el análisis que la población que contempla este estudio es el conformado por mujeres rurales en la faja etaria de 15 a 35 años.

No hay dudas que la información censal da una imagen estática que no explica la realidad cotidiana del mundo rural. Sin embargo, esta manera de caracterizar lo que pasa desde una perspectiva cuantitativa ayuda a tener una primera visión que es necesaria: solo un $9 \%$ de la población vive en las zonas rurales de Argentina, hay más varones que mujeres en el campo y casi el $100 \%$ está alfabetizada. No aparecen los conflictos, las pujas de poder, la relatividad de los hechos ni los límites inciertos entre lo que se dice y pasa, para lo cual es imprescindible realizar análisis cualitativos y estudios de caso.

Aunque a lo largo de este texto se mantendrán las categorías rural y urbana para el análisis de los datos, sobre todo para pensar los cambios ocurridos en las últimas décadas, es necesario señalar que no siempre es adecuada para comprender la realidad del mundo rural del siglo XXI. Hasta los años noventa se asimilaba lo rural con lo agrícola, pero esto se ha ido modificando en las últimas tres décadas al considerar la importancia de las actividades económicas secundarias y terciarias en las zonas rurales, la residencia de habitantes urbanos en el campo y de habitantes rurales con segundas residencias en pequeñas localidades, el empleo de integrantes de agriculturas familiares en actividades no rurales y la radicación de trabajadores/as agrícolas en pueblos y zonas periféricas de las ciudades. Este nuevo escenario da lugar a territorios con entramados y dinámicas más complejas que la de geografías con determinadas condiciones físico-biológicas y criterios poblacionales (Berdegué y Favareto, 2019; Schejtman y Berdegué, 2004). Por otro lado, los criterios de urbano y rural (a su vez, dividido en aislado y agrupado) si bien permiten comparar situaciones, no aportan datos diferenciales entre grandes ciudades y otras de menor envergadura, que ayudarían a analizar algunos procesos -por ejemplo, la migración-que se producen de manera gradual.

Por último, y antes de comenzar, un tema que es necesario señalar y considerar es el lenguaje utilizado en los censos. Como está escrito íntegramente en masculino, resulta distante y dificulta, sobre todo, que las mujeres se reconozcan, por ejemplo, en la categoría "trabajador" y esto es una limitante en general y específica para este análisis. En cuanto al género, sólo reconoce "varones" y "mujeres", y si bien puede interpretarse como auto percibido, el tipo de preguntas y su formulación prácticamente impiden cualquier respuesta fuera de la heteronorma. Sin

\footnotetext{
3 Este documento es el primer capítulo de un libro sobre mujeres rurales, equidad de género y organizaciones que está en elaboración.

4 PROINDER es el Proyecto de desarrollo de pequeños productores agropecuarios. Su ejecución comenzó a fines de 1998 con financiación del Banco Mundial
} 
embargo, hay que destacar que hay cambios activos en el Censo 2010 como es la introducción de la modificación que permitió registrar las parejas de un mismo sexo como tales.

\section{LA CANTIDAD DE POBLACIÓN EN EL ÁREA RURAL}

Para el INDEC, una localidad es urbana o rural según la cantidad de personas que viven en la misma. Un lugar es rural cuando lo habitan menos de 2000 habitantes, y está diferenciada en rural dispersa y rural agrupada. Las áreas rurales dispersas son las zonas en campo abierto donde las viviendas no se encuentran concentrados espacialmente ni conectados entre sí por calles, o donde por la poca densidad poblacional no se le dio nombre a la zona. En cambio, las áreas rurales agrupadas son las poblaciones o conjunto de viviendas donde hay menos de 2000 habitantes (pequeños pueblos o caseríos). En consecuencia, se considera población urbana a toda aquella que esté por encima de los 2000 habitantes.

En el año 1980, el Censo Nacional de Población y Vivienda (CNPyV) encontró que un 17\% de población de Argentina vivía en el área rural; ese porcentaje equivalía a 4.677.235 personas. En el año 1991, la proporción disminuyó a 12,8\% (4.179.418 personas). En el 2001, sobre una población total de 36,2 millones de habitantes, 32,4 millones de personas residían en áreas urbanas (89\%) y 3,8 millones en las áreas rurales (11\%) (Biaggi, Canevari Tasso, 2007). En el 2010, como muestra la tabla siguiente, la población total del país era de 40.117 .096 de personas, y el sector rural sólo representaba el 9\%. Estos porcentajes de población rural muestran la magnitud de la urbanización de Argentina en los últimos 40 años. 


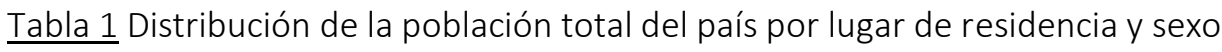

\begin{tabular}{|c|c|c|c|c|c|c|}
\hline \multicolumn{7}{|c|}{ Población total del país en el 2010} \\
\hline \multicolumn{3}{|c|}{$\begin{array}{l}\text { Total de habitantes en el país } \\
\text { Total población urbana } \\
\text { Total población rural }\end{array}$} & \multicolumn{2}{|c|}{$\begin{array}{c}40.117 .096^{5} \\
36.517 .332 \\
3.599 .764\end{array}$} & \multicolumn{2}{|c|}{$\begin{array}{c}100 \% \\
91,03 \% \\
8,97 \%\end{array}$} \\
\hline \multicolumn{7}{|c|}{ Población discriminada por sexo } \\
\hline & \multicolumn{2}{|c|}{ Total } & \multicolumn{2}{|c|}{ Urbana } & \multicolumn{2}{|c|}{ Rural } \\
\hline Varones & 19.523.766 & $48,67 \%$ & 17.575 .993 & $48,13 \%$ & 1.945 .911 & $54,06 \%$ \\
\hline Mujeres & 20.593 .330 & $51,33 \%$ & 18.852 .621 & $51,87 \%$ & 1.737 .648 & $45,94 \%$ \\
\hline \multicolumn{7}{|c|}{ Población rural discriminada por agrupada y dispersa } \\
\hline & \multicolumn{3}{|c|}{ Población en áreas rurales dispersa } & \multicolumn{3}{|c|}{ Población en áreas rurales agrupada } \\
\hline Varones & \multicolumn{2}{|c|}{1.278 .692} & $55,79 \%$ & \multicolumn{2}{|c|}{667.219} & $51,02 \%$ \\
\hline Mujeres & \multirow{2}{*}{\multicolumn{3}{|c|}{$\frac{1.000 .300}{2.292 .063(64 \%)}$}} & & 280 & $48,98 \%$ \\
\hline Total & & & & \multicolumn{3}{|c|}{$1.307 .701(36 \%)$} \\
\hline
\end{tabular}

Fuente: Elaboración propia a partir de datos del INDEC. Censo Nacional de Población, Hogares y Viviendas 2010, procesado con Redatam+SP.

Una particularidad de la población rural en Argentina es que el 64\% vive en zonas semipobladas, o lo que se definió anteriormente como rural dispersa, aunque con una gran variabilidad entre las 23 jurisdicciones provinciales ${ }^{6}$. La figura siguiente muestra que las provincias de Corrientes, Chaco, Formosa, Mendoza, Misiones y Tucumán tienen aproximadamente un $80 \%$ de su población rural establecida en áreas dispersas. Lo contrario ocurre en Catamarca, La Rioja y La Pampa donde la mayor parte de los habitantes rurales viven en caseríos (rural agrupada). Estos porcentajes son muy similares a los del Censo 2001 (Ver Anexo 1).

\footnotetext{
${ }^{5}$ La proyección del INDEC para el 1 de julio del 2020 es de 45.376 .763 habitantes (INDEC, 2013).

${ }^{6}$ Existe una 24a jurisdicción que es la Ciudad Autónoma de Buenos Aires, que no se toma en cuenta en este estudio por no tener áreas rurales.
} 
Figura 1 Porcentaje de población rural agrupada y dispersa según la provincia

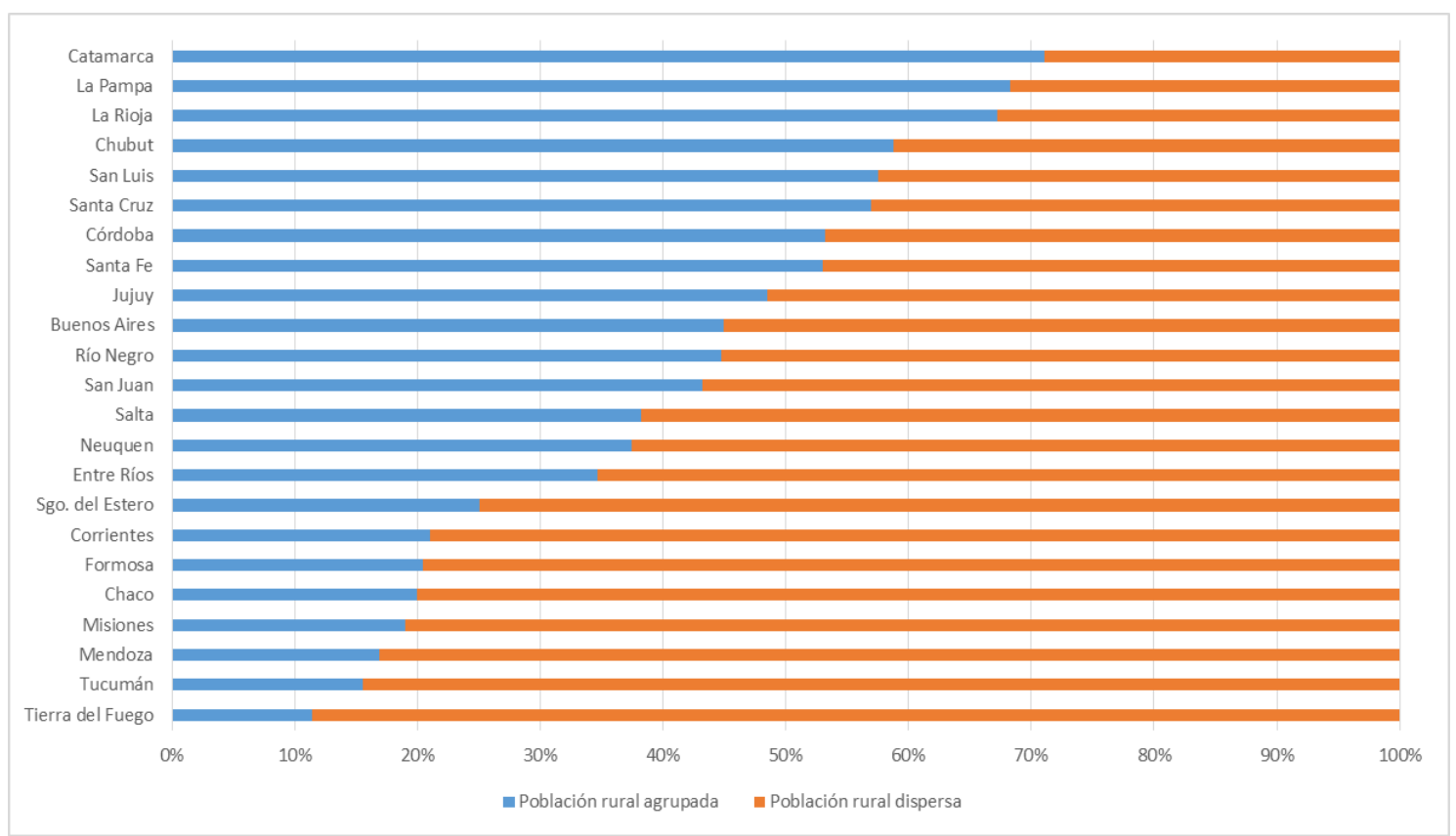

Fuente: Elaboración propia a partir de datos del INDEC. Censo Nacional de Población, Hogares y Viviendas 2010, procesado con Redatam+SP.

Como ya se ha mencionado, otra característica de la población rural es que la cantidad de varones es superior a la de mujeres. Tanto en el Censo 2001 como en el Censo 2010, en la mayoría de las provincias, la población femenina rural es menor al $48 \%$ salvo en algunas que apenas superan esa barrera, como Jujuy (48,4\%), Mendoza (48,5\%), Santa Fe (48,2\%) y Tucumán (48,5\%).

Un cambio que presenta el último censo es la diferencia de proporciones de mujeres entre las áreas agrupadas y dispersas. En las agrupadas, tanto en el 2001 como en el 2010, es entre 48 y $49 \%$ en la mayoría de las provincias. En cambio, en las zonas rurales dispersas disminuyó la proporción; en el 2010 era del $44 \%$ mientras que 10 años atrás era del $48 \%$. Aunque no es posible establecer la dirección del flujo de mujeres que dejaron las áreas rurales dispersas, es probable que sean parte de la población rural que dejó el campo para ir a las ciudades entre el 2001 y 2010.

\section{El descenso de la población rural}

La preferencia de los/as habitantes hacia formas urbanas de residencia y de vida es uno de los cambios más significativos de la sociedad argentina a partir de la mitad del siglo XX, cuando se instala en el país un proceso de migración rural asociado al impacto del desarrollo de la industria nacional en los principales centros urbanos.

El primer censo de población en Argentina se realizó en 1869. En ese año, el $71 \%$ de la población era rural, y cuando se llevó adelante el segundo censo en 1895 había descendido a 62\%. Sin embargo, las operaciones estadísticas de 1869 y 1895 constituyeron censos solamente para el caso de la población de los territorios controlados por el Estado (principal pero no exclusivamente blanca) y solo estimaciones en lo que se refiere a la población de los territorios no controlados (principal pero no exclusivamente indígena) (Otero, 1998). A partir de comienzos del siglo XX, la tendencia de concentración de población en grandes ciudades como Capital Federal (hoy, Ciudad

\footnotetext{
${ }^{7}$ Respecto a la provincia de Tierra del Fuego, Antártida e Islas del Atlántico Sur (que se abrevia de ahora en más en este texto como Tierra del Fuego), hay una inconsistencia en los datos del Censo del 2010. En las tablas generales consultadas en https://www.indec.gob.ar/indec/web/Nivel4-Tema-2-18-77 se registran 1500 personas en el sector rural, pero al hacer los cruzamientos de REDATAM, éstas suben a 6219. Se considera que el valor correcto es el primero.
} 
Autónoma de Buenos Aires) y Gran Buenos Aires principalmente y otras como Santa Fe, Rosario y Córdoba fue irreversible, quedando un 47\% de habitantes en las áreas rurales en el Censo 1914 y de 39\% en el Censo 1947 (Vicien, 1951).

Con la propuesta de analizar el despoblamiento en Argentina como un proceso histórico, en el cuadro siguiente se compara la cantidad de población urbana y rural desde el primer censo en 1869, sabiendo de sus limitaciones, hasta el año 2010.

Tabla 2 Total y porcentaje de habitantes por lugar de residencia urbano y rural y total de habitantes en el territorio nacional según los años que se realizaron los CNPHyV en Argentina.

\begin{tabular}{|c|c|c|c|c|c|}
\hline \multirow{2}{*}{$\begin{array}{c}\text { Año del } \\
\text { CNPHyV }\end{array}$} & \multicolumn{2}{|c|}{ Área Urbana } & \multicolumn{2}{c|}{ Área Rural } & $\begin{array}{c}\text { Total de } \\
\text { habitantes }\end{array}$ \\
\cline { 2 - 6 } & $\begin{array}{c}\text { Total } \\
\text { habitantes }\end{array}$ & $\begin{array}{c}\text { Porcentaje } \\
\%\end{array}$ & $\begin{array}{c}\text { Total } \\
\text { habitantes }\end{array}$ & $\begin{array}{c}\text { Porcentaje } \\
\%\end{array}$ & \\
\hline 1869 & 496.860 & 29 & 1.238 .645 & 71 & 1.735 .505 \\
\hline 1895 & 1.480 .980 & 37 & 2.473 .931 & 63 & 3.954 .911 \\
\hline 1914 & 4.147 .570 & 53 & 3.737 .667 & 47 & 7.885 .237 \\
\hline 1947 & 9.894 .951 & 61 & 6.213 .622 & 39 & 16.108 .573 \\
\hline 1960 & 14.758 .341 & 74 & 5.252 .198 & 26 & 20.010 .539 \\
\hline 1970 & 18.453 .508 & 79 & 4.910 .005 & 21 & 23.364 .513 \\
\hline 1980 & 23.196 .380 & 83 & 4.751 .065 & 17 & 27.947 .446 \\
\hline 1991 & 28.701 .665 & 88 & 3.913 .863 & 12 & 32.615 .528 \\
\hline 2001 & 32.271 .516 & 89 & 3.988 .614 & 11 & 36.260 .130 \\
\hline 2010 & 36.506 .557 & 91 & 3.610 .539 & 9 & 40.117 .096 \\
\hline
\end{tabular}

Fuente: Elaboración propia a partir de Vicien (1951), Dirección Nacional de Estadísticas y Censos (S/F), INDEC (1973; 1983; 1992) y los Censo Nacional de Población, Hogares y Viviendas 2001 y 2010, procesados con Redatam+SP.

La mayor tasa de urbanización se alcanza en el período intercensal 1947-1960, para llegar a 1960 con un porcentaje de población urbana del $74 \%$. A partir de la década del sesenta, la pérdida de población rural no mantuvo ritmos constantes, sino que disminuyó a través de los años en forma diferencial, con un período más crítico en la década del ochenta y noventa como se observa en la Tabla 2.

Entre el 2001 y 2010, la población del país se incrementó un 10,6\%, cifra que representa un crecimiento de 3.856.966 personas. En ese mismo período, la población urbana aumentó un $12,8 \%$ (4.085.382 personas) mientras que la rural perdió 228.416 personas $(-5,9 \%)$. Es decir, el crecimiento poblacional de esta primera etapa del siglo XXI se verificó en el espacio urbano, poniendo en evidencia que la migración del campo a las ciudades mantuvo la tendencia de décadas anteriores. Esto expresa que las ciudades son más atractivas por el crecimiento y mejoramiento de la calidad de servicios de educación, salud, vivienda e infraestructura sumado al cierre de industrias regionales, así como la más reciente tecnificación y elevada concentración económica de las actividades rurales y la absorción de pequeñas localidades rurales por centros urbanos (INDEC, 2015).

Aunque la tendencia del crecimiento de las ciudades ocurre en toda América Latina, el proceso en Argentina es más acelerado en comparación a la mayor parte de los países de la región, donde Paraguay y Ecuador superan el $36 \%$ de habitantes en el medio rural y los vecinos Brasil y Chile alcanzan un porcentaje aproximado entre 12,5 y 13,5\% respectivamente (Banco Mundial, 2020).

En Europa, la migración campo-ciudad comenzó en el siglo XIX cuando los habitantes de las áreas rurales constituyeron la fuerza de trabajo fundamental para el desarrollo de la industria, siendo la concentración de población vital para el sistema capitalista. A este proceso se sumó la modernización tecnológica en el sector agropecuario de la segunda mitad del siglo XX, que 
implicó principalmente menos oferta de empleo y apuntaló la tendencia hacia una mayor urbanización. Sin embargo, actualmente en la Unión Europea, el porcentaje de personas en las zonas rurales no es tan baja como en nuestro país porque el $40 \%$ de la población vive en ciudades, casi el $28 \%$ en zonas rurales y el $32 \%$ en zonas denominadas "intermedias" como suburbios o pequeñas ciudades (Eurostat, 2015).

En Argentina, la migración campo-ciudad de las últimas décadas se relaciona con la disminución de la cantidad de explotaciones agropecuarias (EAPs) ${ }^{8}$. En 1988, existían 421.221 EAPs en todo el país. En el 2002, se redujeron a 333.533 EAPs para llegar al 2018 con 250.881 EAPs en el territorio nacional. El descenso del número de explotaciones agropecuarias no está vinculado a una disminución significativa de la superficie en producción, sino a un proceso de concentración de la propiedad de la tierra (Biaggi, 2018). Esta caída en el número de EAPs tuvo consecuencias principalmente para las producciones familiares y campesinas tanto de la región pampeana como de zonas anteriormente marginales para la agricultura. El primer efecto visible del descenso del número de explotaciones agropecuarias fue una disminución de familias que tenían como su lugar de residencia al campo.

La modernización tecnológica que acompañó este proceso también afectó la demanda de trabajadores/as, ya que las innovaciones en maquinaria y agroquímicos principalmente redujeron la necesidad de asalariados/as y esto ha sido otro motivo de emigración. En varias actividades agrarias, en especial en los casos que la demanda de trabajo es estacional, intermitente y concentrada (generalmente en la época de cosecha), la disminución de la población rural se compensó con la incorporación de mujeres y varones que viven en pequeñas ciudades o pueblos cercanos a empresas agrícolas o complejos agroindustriales (Crespo Pazos, 2015).

\section{LA CANTIDAD DE MUJERES}

Las características geográficas y climáticas influyeron en el poblamiento del territorio argentino durante toda su historia. Los climas templados y las llanuras fértiles estimularon los asentamientos mientras que los climas fríos, las áreas semiáridas y áridas y las grandes alturas constituyeron barreras para la instalación de población. En el Censo 2010 se observa que en este siglo se mantienen las disparidades entre las diferentes regiones. La Región Pampeana sigue siendo la más poblada, con un $59 \%$ de la población de Argentina, aunque mayormente concentrada en la ciudad de Buenos Aires y los 24 partidos del conurbano bonaerense. La Región Noroeste (NOA) tiene 12,2\% y el Noreste (NEA) tiene el 9,2\% del total nacional. Cuyo, la región de mayor aridez, tiene un 7,1\% del total, mientras que la Región Patagónica posee el 5,2\% del total nacional ${ }^{9}$.

\footnotetext{
${ }^{8}$ Las EAPs (explotaciones agropecuarias) son la unidad de medida de los censos agropecuarios, y se definen como la unidad de organización de la producción de más de $500 \mathrm{~m}^{2}$ (terrenos no necesariamente contiguos) que produce bienes agrícolas, pecuarios o forestales destinados al mercado (INDEC, 2019).

${ }^{9}$ La Región Pampeana está conformada por las provincias de Buenos Aires, Santa Fé, Córdoba, La Pampa y Entre Ríos. Entre Ríos es una provincia que tiene características similares a las otras de la Región Pampeana, aunque con una historia que la une a las provincias de la Región Nordeste. La Región Nordeste (NEA) está conformada por las provincias de Formosa, Misiones, Corrientes y Chaco. La Región Noroeste (NOA), por las provincias de Jujuy, Salta, Catamarca, Santiago del Estero, La Rioja y Tucumán. La Región de Cuyo, por las provincias de Mendoza, San Luis y San Juan. La Región Patagónica comprende las provincias de Neuquén, Río Negro, Chubut, Santa Cruz y Tierra del Fuego.
} 
Figura 2 Porcentaje de población rural en el año 2001 y 2010.

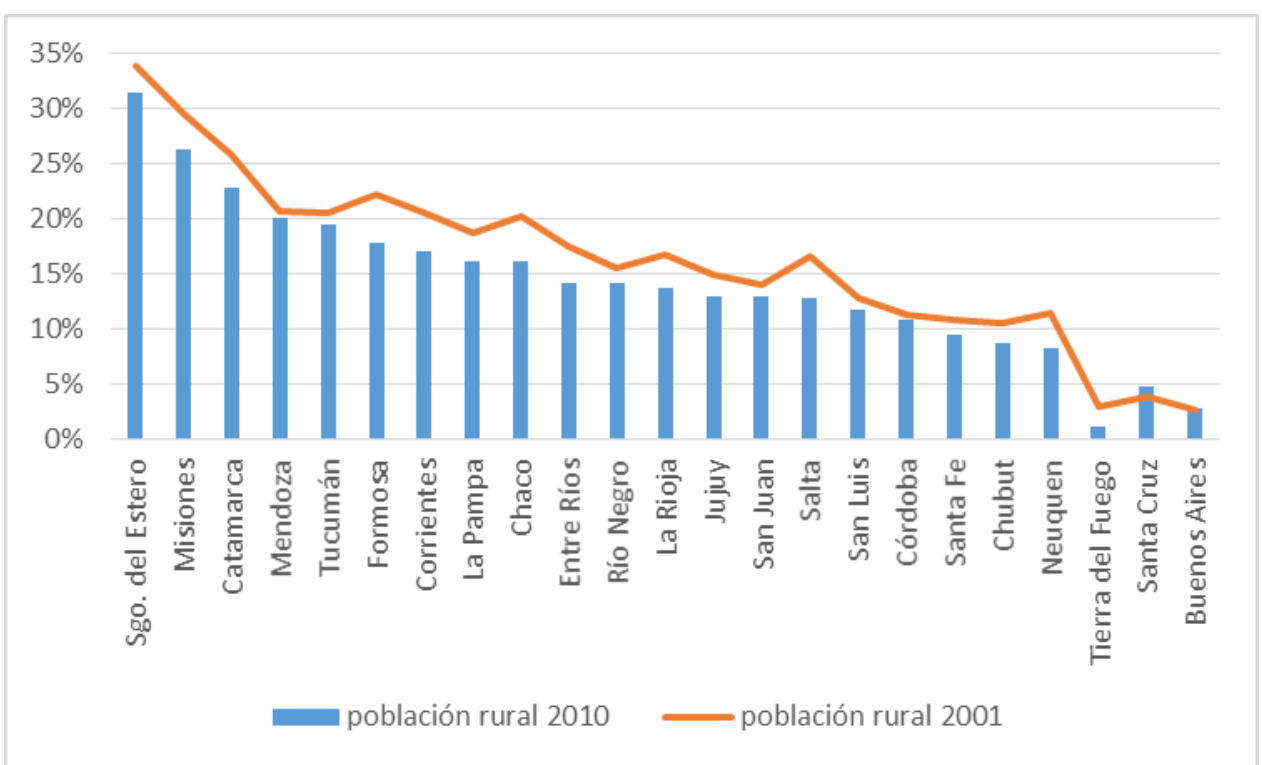

Fuente: Elaboración propia a partir de datos del INDEC. Censo Nacional de Población, Hogares y Viviendas 2001 y 2010, procesado con Redatam+SP

Santiago del Estero, Misiones y Catamarca son las provincias que registraron en el 2010 la más alta proporción de población rural, con valores que representan entre el 25 y 30\% de la población total de cada provincia. En Santiago del Estero y Misiones, la residencia es en su gran mayoría a campo abierto (población rural dispersa), mientras que en la provincia de Catamarca una parte importante de los/as pobladores rurales vive en localidades pequeñas con menos de 2.000 habitantes (población rural agrupada).

No es posible hacer un análisis regional de la reducción de habitantes rurales porque las dos provincias con mayor disminución de población rural entre 2001 y 2010 son Neuquén y Chaco, representantes de la Patagonia y del Nordeste del país. Neuquén descendió casi en un $16 \%$ la cantidad de habitantes rurales entre ambos censos, producto de un proceso creciente de urbanización relacionado con la migración de los/as pequeños/as productores a aglomerados urbanos, la reducción del empleo en las agriculturas familiares junto al predominio de formas más empresariales de organización productiva (FAO, 2015). Chaco llega al 2010 con un 15\% menos de habitantes en el campo que en el anterior censo de población por un proceso de migración hacia las ciudades acelerado y por una tasa de crecimiento intercensal menor que la tasa nacional (Díaz Langoum Cicciaro y Zolotow, 2013).

La tercera provincia con la mayor disminución de la población rural fue Entre Ríos, que tenía 61\% de habitantes en las áreas rurales a comienzos de siglo XX y llegó a un 14,3\% casi cien años después, con un fuerte descenso a partir de los años 2000 de producciones familiares dedicadas a la avicultura, al tambo y a la agricultura en pequeña escala (Peretti et al., 2019; Craviotti y Pardías, 2017).

En Salta también hay una disminución de la población rural por desmontes y al avance de la tecnificación de las principales actividades agrícolas, con el correlato de menos opciones laborales para los habitantes rurales y una mayor urbanización (Klarik, 2019). Formosa no escapó a la tendencia de crecimiento de sus principales ciudades con varones y mujeres provenientes del campo, teniendo, según el Censo 2010, solo un 18\% de habitantes rurales (Blanco y Ramirez, 2014). Porcentaje similar en Corrientes, que también tuvo una contracción su población rural por razones similares a las ya mencionadas (Vallejos et al., 2016).

Las demás provincias presentan porcentajes similares de población rural que en el 2001 o con disminuciones menos alarmantes. Un caso particular es Santa Cruz, que había sido la provincia 
que más redujo su población rural entre 1991 y 2001, y que en el 2010 aumenta un 41\% el número de habitantes rurales pasando de 7.596 personas en 2001 a 10.721 en 2010 (INDEC, 2015). Esto probablemente se relacione al aumento de la tasa de empleo en la provincia, que se incrementó en un 14,6\% respecto a la tasa del año 2001 a partir de nuevos puestos de trabajo formales en el sector privado y el significativo número de personas empleadas en la administración pública provincial (INDEC, 2012). Aunque la información del CNPHyV 2010 no contiene datos respecto a la población nacida en otras provincias, la información de referentes de la provincia indica que muchos trabajadores/as de obras en construcción de infraestructura hidroeléctrica provenientes de otros territorios de Argentina se instalan en "villas temporarias" de menos de 2000 habitantes que se consideran lugares rurales para el INDEC clasifica como rurales.

En el proceso de dejar el campo e ir a las ciudades, históricamente han sido las mujeres quienes lo han hecho en un mayor porcentaje, porque son más afectadas por la carencia de fuentes de empleo, encontrando una mayor diversidad de oferta en las ciudades. Al ser las responsables de las tareas de cuidado del grupo familiar, sufren más las dificultades de acceso a los servicios de salud, que se ven acentuados cuando no hay medios de transporte, además de la inexistencia de sistemas de seguridad jurídica pública en el ámbito rural (Biaggi, 1996; Biaggi, Canevari y Tasso, 2007; Linardelli, 2019). El proceso de expansión de empresas agropecuarias y concentración de la tierra en las últimas décadas del siglo XX tuvo como consecuencia una disminución de familias en la gestión productiva agraria, que significó una desvinculación femenina de la gestión de la tierra. Como información positiva, los datos del Censo 2010 muestran una tendencia menos pronunciada en la migración de mujeres desde a las áreas rurales a las urbanas entre los dos últimos censos.

Hay un grupo de provincias que tienen más mujeres en las áreas rurales en el 2010 que en el 2001, aunque son aumentos poco significativos. Son los casos de Santiago del Estero, Chubut, Misiones, Mendoza y Tucumán, con una mención especial a San Luis que a pesar de un proceso de urbanización significativo aumentó la cantidad de mujeres en el campo en comparación a 10 años atrás. Santa Cruz, que como dijimos tiene un 41\% más de habitantes rurales que en el 2001, ha aumentado considerablemente el número de mujeres pasando de 2273 mujeres a 4334 en el 2010. Las provincias de Neuquén, Chaco y Formosa, que se las mencionó por la disminución de su población rural total, han tenido migración de mujeres, pero en menor proporción que la de los varones.

Las mujeres que viven en el campo están principalmente en las zonas rurales agrupadas, y en las zonas rurales dispersas hay una menor presencia de población femenina. Así es en las provincias de la Región Pampeana y en la Región del NEA. En el NOA, aunque se mantiene la misma tendencia hay excepciones en los poblados rurales de los departamentos cordilleranos de Salta, Catamarca y La Rioja que cuentan con una proporción media-baja a baja de mujeres que puede estar asociado al desarrollo de la minería en esa región. En Cuyo, las localidades rurales con predominio femenino se ubican principalmente en Mendoza y en el este de San Juan. En Patagonia, la disparidad de género se presenta de manera generalizada en las áreas con y sin agrupamientos poblacionales (Alegre, 2015).

\section{LA EDAD DE LAS MUJERES Y DE LOS VARONES EN EL ÁREA RURAL}

La pregunta que continúa en este análisis es qué edad tienen los varones y, en especial, las mujeres que se quedan en el campo. 
Figura 3. Pirámide poblacional 2001 y pirámide poblacional 2010 de las áreas rurales

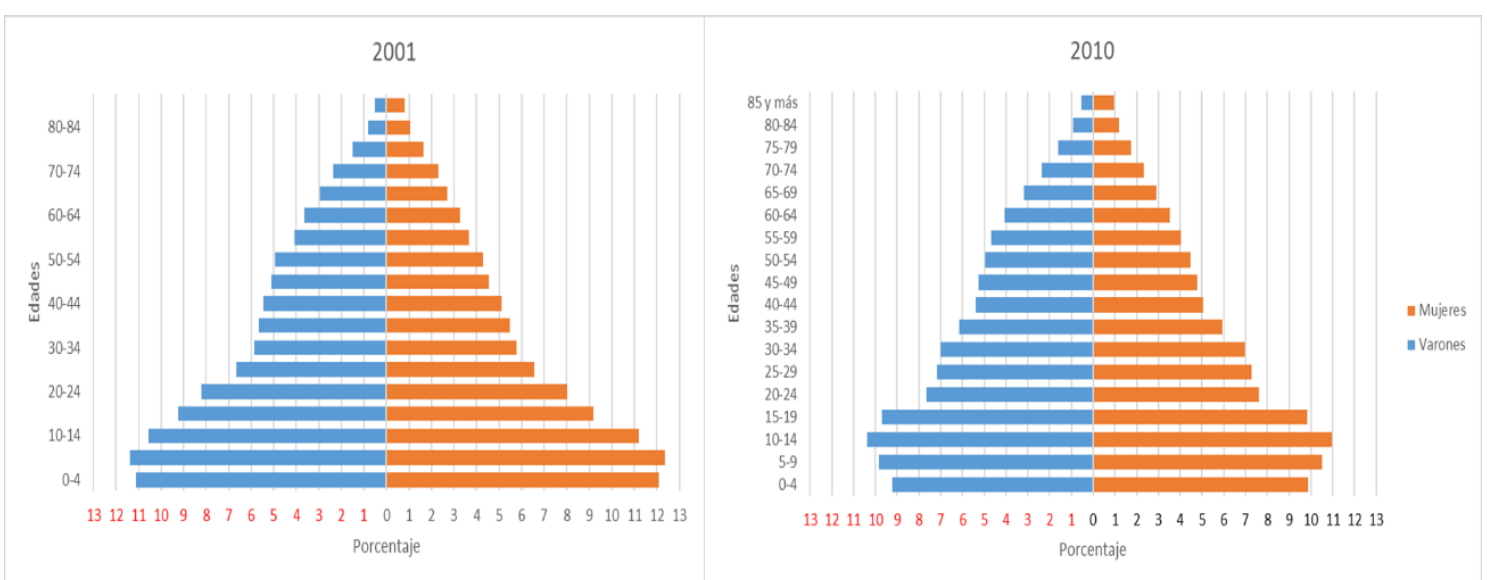

Fuente: Elaboración propia a partir de datos del INDEC. Censo Nacional de Población, Hogares y Viviendas 2001 y 2010, procesado con Redatam+SP

La primera conclusión que nos dan las pirámides poblacionales es que la proporción de niños/as entre 0 a 14 años en el Censo 2010 es menor a la que había en el 2001. Este grupo representaba el 34\% de la población en el 2001 y en el 2010 es el 30\%. Por lo tanto, hay un achicamiento de la base de la pirámide del 2010 que da cuenta de un proceso de menores tasas de natalidad.

La segunda conclusión es que no hay una mayor retención de jóvenes en el campo entre los dos últimos censos. Las ciudades siguen siendo atractivas para la juventud, probablemente más que antes por la influencia de los medios de comunicación y porque para muchos/as continúa apareciendo como un mejoramiento de su situación social. A este factor, hay que sumar que en la ruralidad las prácticas de las personas son inscriptas con más fuerza según estereotipos de género y normas de conducta heterosexual, y cuando los/as jóvenes no cumplen las expectativas y no se acomodan a la comunidad, hay una tendencia a la emigración.

Al igual que en el 2001, los varones superan a las mujeres en todos los grupos de edad en las áreas rurales. A partir de los 40 años, la proporción de población masculina es aún mayor mostrando una disminución de la femenina relacionada con una migración rural-urbana que es corroborada por un mayor porcentaje de mujeres en esa franja etaria en las ciudades. En muchos casos, las mujeres se mudan a localidades cercanas para que sus hijos/as puedan estudiar, dejando las actividades agropecuarias a cargo de los varones de la familia. En estos últimos años, la necesidad de una mejor conectividad y el acceso a las nuevas tecnologías también se presentó como una razón para que adolescentes e hijos/as jóvenes busquen salir del campo. Después de los 65 años de edad, las mujeres llegan a ser el 60\% de la población urbana y comienza a aumentar su proporción en las zonas rurales; esto se explica por una tasa de mortalidad diferencial para varones y mujeres ${ }^{10}$.

\footnotetext{
10 La tasa de mortalidad es el cociente entre el número de defunciones ocurridas durante un período determinado, generalmente un año calendario, y la población media del período (INDEC, 2021). En el 2017, la tasa de mortalidad era de 17,4 para las mujeres y de 32,3 para los varones entre 65 a 74 años a nivel nacional (INDEC, 2021).
} 
Figura 4 Porcentaje de varones y mujeres en las áreas urbanas y rurales por grupos de edad

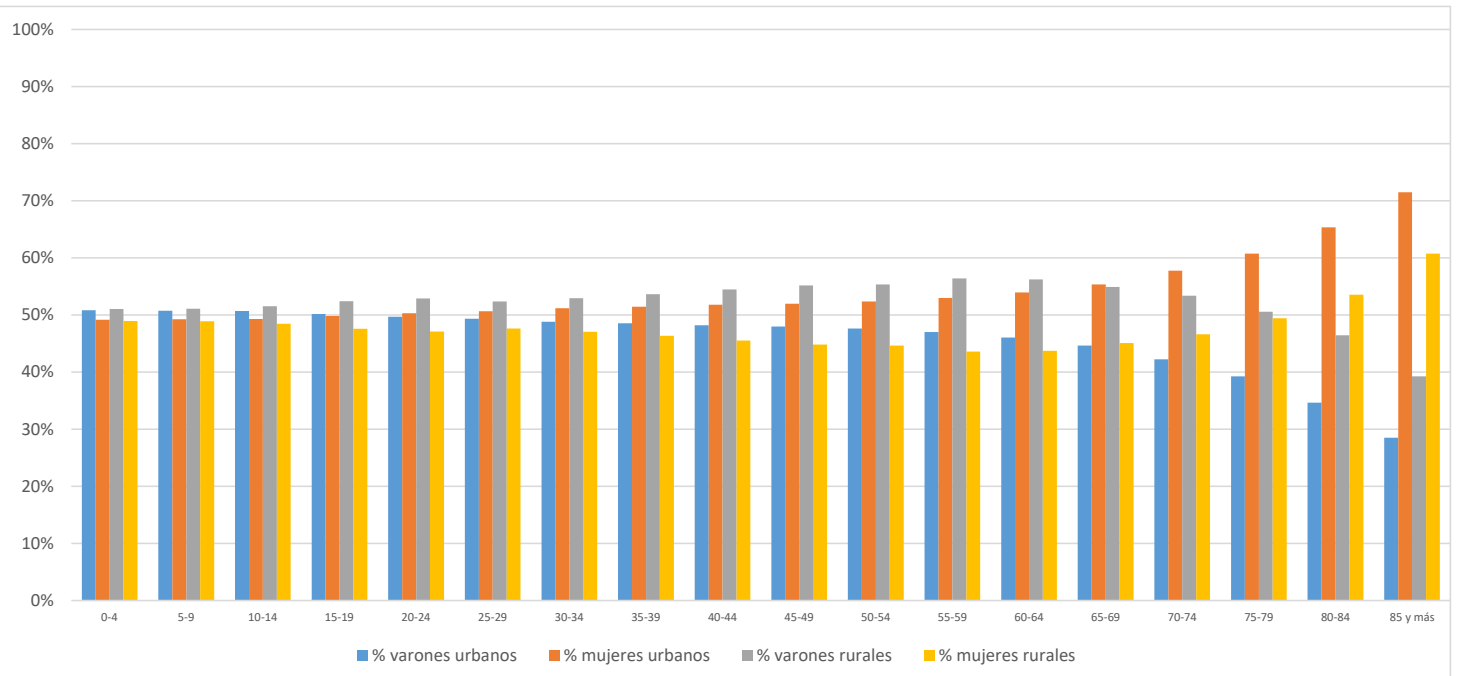

Fuente: Fuente: Elaboración propia a partir de datos del INDEC. Censo Nacional de Población, Hogares y Viviendas 2010, procesado con Redatam+SP

La figura anterior muestra una proporción menor o similar de mujeres que de varones en las ciudades hasta los 20 y 24 años, y después de los 25 años siempre es mayor el porcentaje de mujeres en las zonas urbanas. Por el contrario, en las áreas rurales es a partir de los 15 años cuando la proporción de mujeres comienza a disminuir con una reducción importante después de los 40 años. Por lo tanto, hay cada vez más varones solos en el campo lo que no es un indicador positivo para el arraigo rural y es uno de los factores que incide con la caída de la tasa de natalidad anteriormente mencionada ${ }^{11}$.

En los análisis siguientes sobre acceso a la educación, el empleo y los porcentajes de NBI de las áreas rurales, se intenta dar una explicación a este proceso de éxodo femenino que no es actual y que parece haber alcanzado su máxima expresión en la década del noventa. La situación de desventaja de las mujeres en el campo -mantenimiento de los roles asignados, culturas más patriarcales que en las ciudades, aislamiento con débiles redes sociales y pocas opciones de ocio, deficientes infraestructuras y servicios de salud y un casi inexistente apoyo ante situaciones de violencia, que en algunos casos puede expresarse en una maternidad temprana- refuerza la decisión de las mujeres de migrar, con la ilusión de que la ciudad sea un lugar con más posibilidades de equidad. Son pocas las razones que encaminan a un retorno al campo, y muchas veces cuando lo hacen es para el cuidado de personas dependientes en un contexto de envejecimiento de la población.

\section{LA MATERNIDAD}

El proceso de descenso de la fecundidad en Argentina lleva más de un siglo, y comenzó antes que en el resto de América Latina, excepto Uruguay (Pantelides, 1989). La Tasa Global de Fecundidad (TGF) era de 6,8 en 1869 y llegó a 3,3 en 1947, un nivel que se mantuvo constante hasta 1980 cuando continuó descendiendo. En el período 1990-1995, fue de 2,8 y el INDEC informa un valor de 2,4 hijos/as por mujer con los datos obtenidos tanto en el Censo 2001 como así también en el del 2010 (INDEC, 2021).

En el gráfico siguiente, se muestra la Tasa Global de Fecundidad calculada para los censos 19602010 a nivel nacional, para cada una de las regiones del país y para la Ciudad Autónoma de Buenos Aires (CABA).

\footnotetext{
11 Para una profundización sobre el tema, Alegre (2015) hace un análisis muy detallado de la cantidad de población entre 15 y 34 años en el territorio nacional.
} 
Figura 5 Tasa Global de Fecundidad en los CNPHyV 1960-2010 a nivel nacional, en las regiones NOA, NEA, Patagonia, Cuyo y Pampeana y en la Ciudad Autónoma de Buenos Aires (CABA).

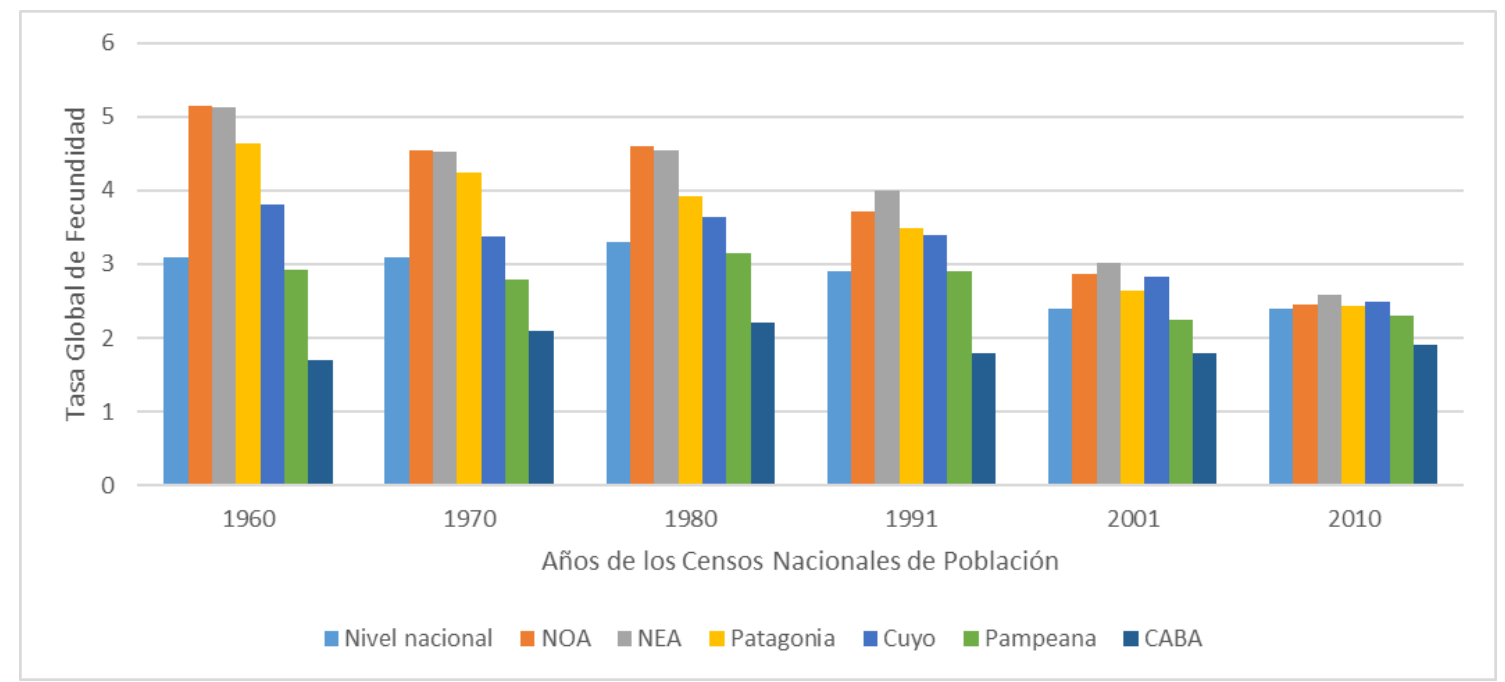

Fuente Elaboración propia a partir de INDEC (2021)

En la figura anterior, se observa que las TGF varían entre las regiones y que siempre es mayor en las provincias que a nivel nacional (tasa que está influida por el bajo valor de la Ciudad Autónoma de Buenos Aires). Hasta el Censo 1991, la TGF era significativamente mayor en aquellas jurisdicciones donde había más población rural. En el 2001 comienzan a equipararse, para llegar al 2010 con TGF casi homogéneas en todo el territorio nacional, donde solo se sigue distinguiendo la Ciudad de Buenos Aires por la baja TGF en comparación al resto del país.

Hay un cambio en los patrones reproductivos en relación con las generaciones de finales del siglo XX que puede ser explicado en parte por el impacto de las políticas públicas en salud sexual y reproductiva desarrolladas en el país. En los últimos 20 años hay más información, el acceso a los métodos anticonceptivos se ha naturalizado en la década pasada, y eso se visibiliza en familias menos numerosas en todo el territorio.

Aunque el Censo 2010 muestra una menor heterogeneidad en la TGF entre provincias, se mantiene un mayor número de hijos/as/es en las mujeres rurales entre 40 y 49 años en comparación a las mujeres urbanas del mismo grupo etario. Esto se debe a que los cambios en los índices de fecundidad se observan en las mujeres más jóvenes y no en las que han concluido la etapa reproductiva, lo cual demuestra que son cambios recientes. Como muestra el gráfico siguiente, en el área urbana, el 70\% de las mujeres de 40 a 49 años tiene entre 1 y 3 hijos/as/es y el 30\% tiene 4 o más hijos/as/es. En cambio, en las áreas rurales el 50\% de las mujeres tiene 4 o más hijos/as/es en el 2010 (Ver Anexo 2).

Esta diferencia de más hijos/as/es en las mujeres rurales en comparación a las urbanas es muy similar a la que informa el Censo 2001. 
Figura 6 Porcentaje de mujeres de 40 a 49 años según la cantidad de hijos/as por lugar de residencia

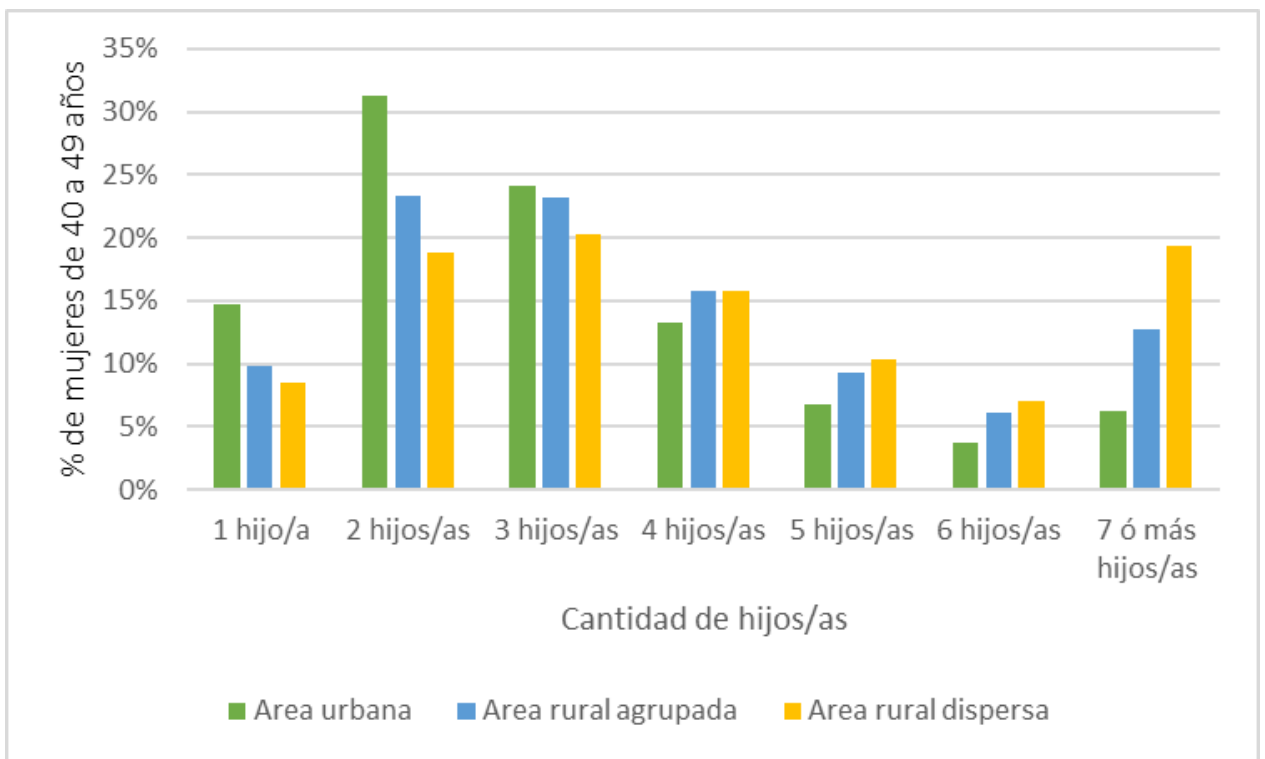

Fuente: Fuente: Elaboración propia a partir de datos del INDEC. Censo Nacional de Población, Hogares y Viviendas 2010, procesado con Redatam+SP

Haciendo un análisis territorial, se encuentra que en las regiones con menos población rural no hay diferencias significativas entre el número de hijos/as/es que tienen las mujeres de 40 a 49 años según el lugar de residencia. Por lo contrario, en las provincias del norte, las mujeres de esa fase etaria que viven en el campo tienen una mayor cantidad de hijos/as/es que en la de las ciudades en todos los casos. En general, en el NOA y NEA se encuentran los porcentajes más altos de mujeres con 4 o más hijos/as/es del país.

Con respecto a la maternidad temprana (15 a 19 años), el Censo 2010 muestra una tendencia decreciente, aunque aún mantiene valores altos porque la tasa de fecundidad adolescente en Argentina (TEFA 15-19 años) fue de 64 por mil en el período 2010-2015, por lo tanto está por encima del promedio mundial (46 por mil) (Frenkel, 2019).

En la figura siguiente, se muestra la proporción de mujeres de 15 a 19 años que tienen hijos/as por lugar de residencia y por provincia según la información de del Censo 2010 (Ver Anexo 3). 
Figura 7 Porcentaje de mujeres de 15 a 19 años con hijos/as por lugar de residencia según provincia

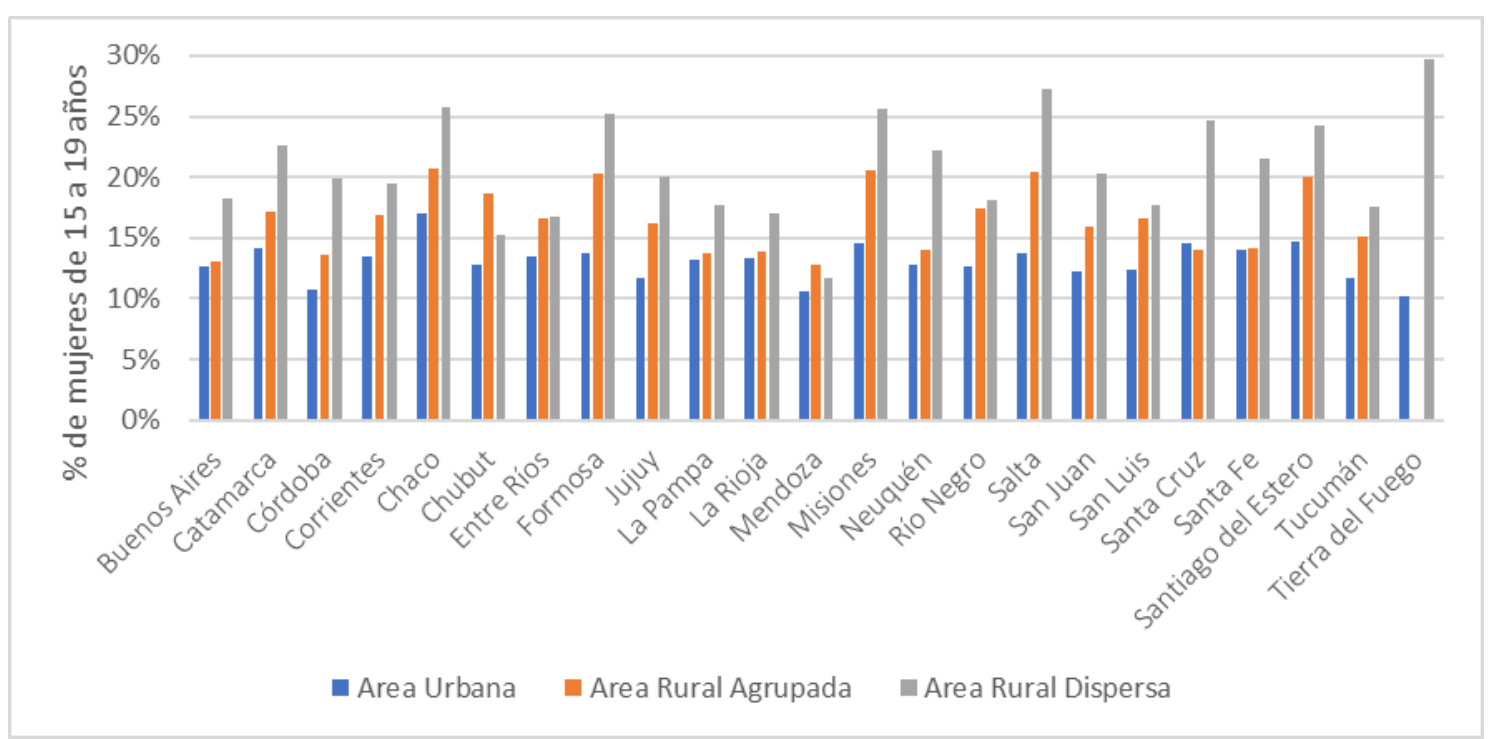

Fuente: Fuente: Elaboración propia a partir de datos del INDEC. Censo Nacional de Población, Hogares y Viviendas 2010, procesado con Redatam+SP

En la mayor parte de las provincias, el porcentaje de mujeres que son madres en edades tempranas muestra las mismas disparidades entre campo y ciudad que las anteriormente mencionadas para cantidad de hijos/as, aunque con diferencias más significativas entre las áreas rurales agrupadas y dispersas. En la figura anterior se observa que hay una mayor incidencia de la maternidad entre las jóvenes de 15 a 19 años que viven en zonas aisladas que en las pequeñas localidades rurales. La región noreste es la que presenta el mayor porcentaje de maternidad temprana, donde Chaco, Formosa y Misiones tienen porcentajes en las áreas rurales dispersas que superan el 25\% de jóvenes de 15 a 19 años con hijos/as. Lo mismo ocurre en Salta y Tierra del Fuego.

Existen limitantes para que los/as adolescentes de las áreas rurales puedan tomar decisiones libres sobre su salud sexual y reproductiva, como es falta de acceso a información y a educación sexual integral en las escuelas, la inexistencia de consejerías dentro de los hospitales y centros de salud, incluyendo la interrupción legal del embarazo en las situaciones previstas en el marco normativo, y la falta de acceso a métodos anticonceptivos gratuitos y probadamente efectivos (Frenkel, 2019) ${ }^{12}$. Los servicios de salud se encuentran en su mayoría concentrados en zonas urbanas y aquellos ubicados en localidades rurales son muchas veces precarios, aunque en estos años han aparecido nuevas formas a través de programas que acercan móviles equipados, personal médico o promotores de salud. El aislamiento disminuye las opciones de entretenimiento, no suele haber lugares donde realizar actividades deportivas o culturales y el consumo de bebidas alcohólicas y relaciones sexuales aparecen casi como únicas actividades satisfactorias. En la problemática del embarazo adolescente también hay que incluir las situaciones donde por falta de oportunidades, la maternidad aparece como una "ilusión" de cambio y, sobre todo, la existencia de embarazos en edades tempranas producto de abusos sexuales, tanto familiares como extrafamiliares.

La maternidad temprana es frecuentemente involuntaria. Según el Programa Nacional de Salud Integral en la Adolescencia (2018), el 58,9\% de los embarazos de las adolescentes de 15 a 19 años son reportados como no intencionales por las adolescentes. La preocupación principal es que compromete las trayectorias de vida de las jóvenes rurales y, en algunos casos, la posibilidad de continuar estudiando e insertarse en puestos de trabajo de calidad, afectando su seguridad

\footnotetext{
${ }^{12}$ En el año 2020, se aprobó la Ley 27610 de Interrupción Voluntaria de Embarazo (IVE). Es de esperar que su efectiva aplicación modifique esta circunstancia.
} 
económica. Puede convertirse en un factor de inequidad de género en los hogares de menores recursos, donde la maternidad a edades tempranas también actúa como refuerzo de roles tradicionales de género, prolongando situaciones de subalternidad y domesticidad que restringen sus derechos en el espacio público (Gogna y Binstock, 2017). Además, hay mayores problemas de salud asociados a la maternidad en las jóvenes.

En este análisis, no se tienen en cuenta los casos de mujeres de 10 a 14 años que tuvieron hijos/as nacidos vivos porque se considera que los mismos son embarazos por abusos sexuales.

\section{LA EDUCACIÓN}

Desde fines del siglo XIX, el sistema educativo en Argentina presenta una dinámica de crecimiento, aunque con períodos de ritmos dispares para algunos niveles y jurisdicciones. Los últimos 20 años han sido especialmente innovadores, caracterizados por una expansión en los territorios del nivel inicial y un incremento en la cantidad de recursos humanos para todos los niveles. Como consecuencia de este proceso, el porcentaje de alfabetización en el país asciende al 98,1\% de la población (INDEC, 2021).

En las áreas rurales, los cambios han sido significativos más allá de que la matrícula disminuyó conforme el país se ha urbanizado. Actualmente, la matrícula de alumnos/as urbana y la matrícula de alumnos/as rural acompaña los porcentajes de población de ambos tipos de residencia, ya que el $91 \%$ de la matrícula del nivel primario acude a escuelas en el ámbito urbano y poco más del 9\% a escuelas rurales. La asistencia de la población a establecimientos escolares de nivel primario, tanto urbana como rural, presenta porcentajes cercanos al 100\%. En cuanto al nivel secundario, la matrícula es baja en las áreas rurales, ya que solamente un 7,5\% de los/as estudiantes del nivel secundario asiste a escuelas en el campo y el $93 \%$ lo hace dentro del ámbito urbano. Como importante, en el período 2001-2010, en todos los establecimientos secundarios rurales, el nivel de asistencia escolar aumentó en el tramo de 12 a 17 años y disminuyó el abandono escolar entre los adolescentes de esa edad (González et al., 2015; Buchbinder, McCallum y Volman, 2019).

Aunque la historia de las escuelas rurales públicas en Argentina comienza a finales del siglo XIX, la educación rural se incorporó formalmente a la agenda educativa a través de su constitución como modalidad a partir de la sanción de la Ley de Educación Nacional ( $\left.N^{\circ} 26.206\right)$ en el año 2006. Esto se realizó a través de distintas acciones a nivel nacional y a partir de acuerdos internacionales que buscaron ubicar a la educación de la población rural en la agenda de los estados, con el objetivo de "reducir las disparidades entre los sexos, entre las regiones, entre las zonas rurales y los centros urbanos" (sobre la Educación, F. M., 2000). La instalación de la modalidad de educación rural en el sistema educativo nacional logró desarrollar formas más adecuadas a las necesidades, particularidades y potencialidades de la población rural en una geografía muy diversa, incluyendo programas y financiamientos para garantizar el cumplimiento de la escolaridad obligatoria, y se definió la importancia de que la escuela rural alcance niveles de calidad equivalentes a sus pares urbanas (González et al., 2015).

Un antecedente específico sobre educación rural en Argentina son las experiencias de las escuelas agrarias con régimen de alternancia, donde el método pedagógico toma a la escuela y a la vida productiva familiar como espacios de formación (Gutiérrez, 2017). El sistema contempla la permanencia del alumnado en el establecimiento en períodos cortos, que se alternan con otros durante los cuales el alumnado regresa al hogar continuando allí el proceso educativo. Este régimen se aplica en algunos secundarios, como las Escuelas de Familia Agrícola en el NEA y los Centros Educativos para la Producción Total (C.E.P.T.) en la provincia de Buenos Aires. En prácticamente todas las escuelas con régimen de alternancia se desarrollan actividades de formación para el trabajo y de extensión y asistencia técnica hacia el medio productivo y social local y plantean como uno de sus objetivos, reforzar el arraigo de los/as jóvenes en la producción familiar y en la zona de residencia (Palamidessi, 2003). En el 2013 se relevó la existencia de 205 escuelas con este régimen en todo el país (González et al., 2015). A la modalidad de escuelas agrarias con régimen 
de alternancia hay que sumar las escuelas técnicas con orientación agropecuaria existentes en las diferentes provincias (Binstock y Cerrutti, 2017).

Una acción en educación rural innovativa previa al Censo 2010 con impacto en los territorios fue la implementación del Proyecto de Mejoramiento de la Educación Rural (PROMER) durante el período 2006 a $2010^{13}$. Las principales acciones de PROMER fueron: a) provisión de materiales didácticos básicos y equipamiento para la enseñanza para todos los niveles de la educación común y especial, bibliotecas y ludotecas escolares, equipamiento tecnológico y multimedia, laboratorios escolares, materiales impresos tanto para docentes como para estudiantes; $b$ ) mejora en las condiciones de la infraestructura escolar existente; c) apoyo al desarrollo de acciones de la modalidad de Educación Intercultural y Bilingüe (EIB) en las escuelas que asisten alumnos de población indígena; y d) financiamiento para el desarrollo de Proyectos Institucionales de Base Local a través de proyectos pedagógicos que articulen el conocimiento cotidiano de la comunidad, con el conocimiento escolar (Olmos y Pallarino, 2019).

La información del Censo 2010 sobre el acceso a la educación permite un análisis imprescindible de las diferencias de género en las áreas rurales, a través de dos aspectos principales: la asistencia de la población a los establecimientos escolares y la tasa de analfabetismo y las posibilidades de continuidad de los estudios finalizado el nivel primario.

El Censo 2010 cuantifica a mujeres y varones de 3 o más años según el lugar de residencia que asiste y asistió a un establecimiento escolar. Se observa que en las zonas urbanas no hay una diferencia significativa entre varones y mujeres que asisten a un establecimiento escolar, tampoco entre los y las que asistieron y ahora no lo hacen ni entre aquellos/as que nunca pudieron hacerlo. El porcentaje de mujeres urbanas que asistía en el 2010 a un establecimiento escolar era de 32,2\% y el porcentaje de varones de $32,7 \%$; el de mujeres que asistieron de casi $65 \%$ y varones de $64,5 \%$ $y$, finalmente, mujeres y varones que nunca asistieron es de $2,8 \%$.

Figura 8 Porcentaje de población de 3 años y más en las categorías Asiste, Asistió y Nunca Asistió según lugar de residencia y sexo.

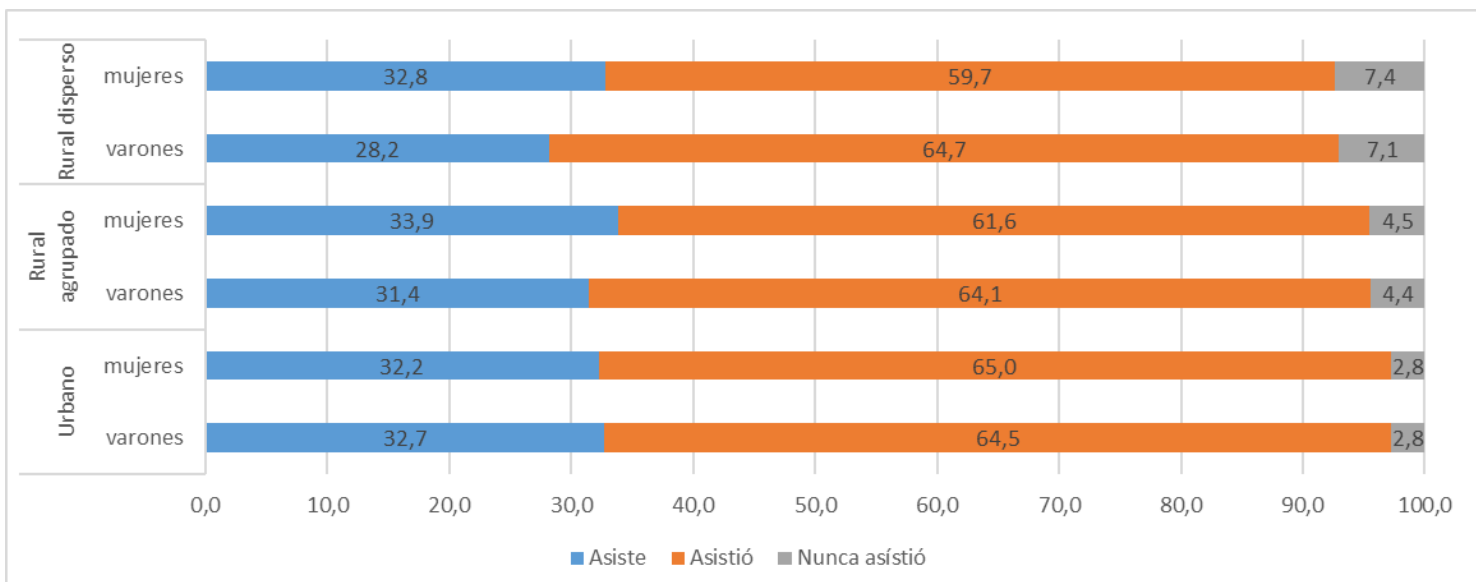

Fuente: Fuente: Elaboración propia a partir de datos del INDEC. Censo Nacional de Población, Hogares y Viviendas 2010, procesado con Redatam+SP

En cambio, en las localidades rurales hay diferencias en la categoría asiste, asistió y nunca lo hizo entre varones y mujeres que se incrementan en la población de las áreas rurales dispersas. En el sector rural agrupado, es mayor el porcentaje de mujeres que asistía a la escuela en el año 2010 que el de varones (33,9\% y 31,4\% respectivamente). Sin embargo, esto no fue siempre así porque

13 El PROMER fue un Proyecto diseñado en el marco del Convenio de Préstamo BIRF 7353-AR, suscripto el 23 de octubre de 2006 entre la República Argentina y el Banco Internacional de Reconstrucción y Fomento (BIRF). La implementación del PROMER entró en vigencia en el año 2007 y se prorrogó hasta el año 2013. En la actualidad se encuentra en vigencia la segunda etapa del proyecto. 
los varones tienen un porcentaje mayor en la categoría asistió $(64,2 \%)$ que las mujeres $(61,6 \%)$, aunque no hay diferencias entre sexos en la categoría nunca asistió (4,4\% y 4,5\%). En las áreas rurales dispersas, se repite la misma situación que en las agrupadas, pero con diferencias entre sexos más significativas; los porcentajes de varones y mujeres que nunca asistieron son muy similares $(7,0 \%$ y $7,4 \%)$, es mayor la proporción de varones que asistieron en el pasado en comparación a las mujeres (65\% y $60 \%$ ) y actualmente es mayor la población de mujeres que de varones que asisten a un establecimiento educativo ( $28 \%$ y $33 \%)$.

Al momento de buscar las causas de esta diferencia en asistencia a un establecimiento educativo, encontramos que los varones jóvenes tienen mayores oportunidades de un ingreso temprano a actividades laborales aún con secundario incompleto y esta es una razón por la que no terminan los estudios. Las mujeres, por su lado, tienen más dificultades para conseguir trabajo, incluso habiendo finalizado la educación obligatoria. Frente a los problemas para la inserción laboral, las jóvenes expresan la voluntad y la necesidad de seguir estudiando (Alegre, 2015; González et. al, 2015).

Con respecto al analfabetismo, existen diferencias también según el lugar de residencia para la población mayor de 14 años y es una dimensión que se relaciona con la categoría "Nunca Asistió" descripta en el cuadro anterior. En las áreas urbanas, hay un 1,7\% de analfabetos, en las áreas rurales agrupadas un 3,7\% y en las áreas rurales dispersas es de 6,4\%. En esta dimensión de análisis no hay diferencias significativas entre sexos en los diferentes lugares de residencia y es un cambio en comparación a los censos de población anteriores, cuando el acceso a la educación era preferentemente masculina y el porcentaje de mujeres analfabetas o semi analfabetas era mayor que el de varones. Las mujeres han presentado históricamente una tasa de analfabetismo mayor que los varones, pero la brecha se ha ido achicando con el tiempo: en 1970 las tasas por sexo eran $8,3 \%$ y 6,5\%, en mujeres y varones, respectivamente, y en 1990 la diferencia era sólo de 4,9\% a $4,5 \%$ (UNESCO, 1991). En el 2001, la tasa de analfabetismo para varones y mujeres se iguala en $2,6 \%$ y en el 2010 , la diferencia es a favor a de las mujeres porque solo el 1,8\% es analfabeta y en el caso de los varones, es casi $2 \%$ (INDEC, 2021).

Antes de analizar las posibilidades de continuidad en el sistema educativo de las mujeres y varones de las áreas rurales, es importante recordar que en la década de los noventa, con la propuesta del mejoramiento en el acceso y de ampliar la oferta educativa, se sancionó la Ley Federal de Educación 24.195/93, o EGB como se llamó comúnmente. La Ley Federal de Educación produjo una modificación estructural en lo que fuera el modelo de organización tradicional de la educación y estuvo en vigencia entre 1994 y 2006 con diferencias de implementación a lo largo del territorio nacional. Esta Ley extendía la obligatoriedad de la educación a 10 años, lo que implicaba la existencia de un Nivel Inicial ( 3 a 5 años de edad), un ciclo de Educación General Básica 1 (EGB 1) desde los 6 a los 8 años, un ciclo EGB 2 de 9 a 11 años y un tercero (EGB 3) de 12 a 15 años. En algunas escuelas rurales que anteriormente sólo eran primarias, se implementaron los tres niveles de EGB (hasta noveno año) y esto facilitó que las y los jóvenes rurales tuvieran 2 años más de educación formal. Sin embargo, hubo casos donde las escuelas rurales que tenían séptimo grado quedaron solo brindando educación hasta el segundo ciclo (EGB 2) y, por lo tanto, los/as niños/as que por dificultades de acceso no podían continuar con EGB 3 perdieron un año de escolaridad ${ }^{14}$.

En algunas provincias, hubo sistemas particulares de fortalecimiento de la educación rural. Por ejemplo, el Ministerio de Educación, Ciencia y Tecnología, en articulación con los ministerios provinciales, implementó una propuesta específica para promover la extensión de la escolaridad

\footnotetext{
14 En mayo del año 2006, el gobierno nacional derogó la Ley 24.195. El 14 de diciembre del mismo año, el Congreso Nacional sancionó la ley 26.206, Ley de Educación Nacional. A partir de la nueva ley, la estructura del Sistema Educativo Nacional tiene nuevamente cuatro niveles: Inicial, Primaria, Secundaria y Superior.
} 
obligatoria en zonas rurales aisladas. Esta propuesta fue conocida como Proyecto 7 y llegó a abarcar 2500 escuelas de dos tercios de las provincias argentinas con niveles de cobertura diversos en cada una de ellas. El proyecto preveía que las y los jóvenes rurales cursen la EGB3 en la misma escuela en la que cursaron la EGB1 y 2. Para esto, en cada institución se designó un/a maestro/a tutor/a que debía garantizar el seguimiento del estudiantado y, por otra parte, un equipo de profesores/as itinerantes de diferentes áreas curriculares debía concurrir periódicamente a un conjunto de escuelas en una misma zona. Sin embargo, no se consideró el traslado de los docentes que no siempre contaban con movilidad, por lo que se suspendían las clases y las/os jóvenes terminaban abandonando.

Cuando en el Censo 2010 se pregunta por el nivel de educación, se lo hace a la población mayor de 25 años que accedió al cambio del sistema educativo de la Ley de Educación. La información muestra que la población rural, a pesar de los cambios que hubo entre 1994 y 2006, sigue siendo postergada en el acceso a educación finalizado la escuela primaria. Hubo un mejoramiento en la cobertura educativa y en los índices de medición de aprendizaje, pero aún hay una brecha ruralurbana que vulnera la igualdad de oportunidades. Es un reflejo de la falta de equidad "geográfica" de Argentina y es una de las razones por lo cual las familias prefieren vivir en las ciudades antes que en el campo. Las dificultades de acceso a la educación secundaria y superior que se evidencian para la población rural en el país son similares a lo que ocurre a nivel mundial, debido fundamentalmente a las características estructurales que presentan las regiones rurales (baja densidad y dispersión poblacional, grandes distancias entre centros poblados, carencia de infraestructura básica, mayores costos per cápita para la provisión de servicios, etc.) y al marcado sesgo urbano presente en las políticas implementadas por los diversos estados nacionales (Olea, 2013).

En la figura siguiente se encuentra la información del Censo 2010 de la población de 25 años y más según máximo nivel educativo alcanzado que puede ser escuela primaria y EGB, escuela secundaria, educación superior no universitario y universidad y estudios post universitario, discriminado por el lugar de residencia (urbano, rural agrupado y rural disperso) y por el sexo. Se observa que mientras en las áreas urbanas aproximadamente un $40 \%$ de la población cursó únicamente escuela primaria o EGB, ese porcentaje aumenta a $62 \%$ en las áreas rurales agrupadas y a $75 \%$ en las dispersas. Por lo tanto, un $60 \%$ de la población que vive en las ciudades continúa estudiando mientras que los/as jóvenes del campo solo lo hacen en un $38 \%$ en las localidades rurales y un $25 \%$ en el campo profundo (Ver Anexo 4).

Figura 9 Porcentaje de población de 25 años y más según máximo nivel educativo alcanzado por lugar de residencia y sexo

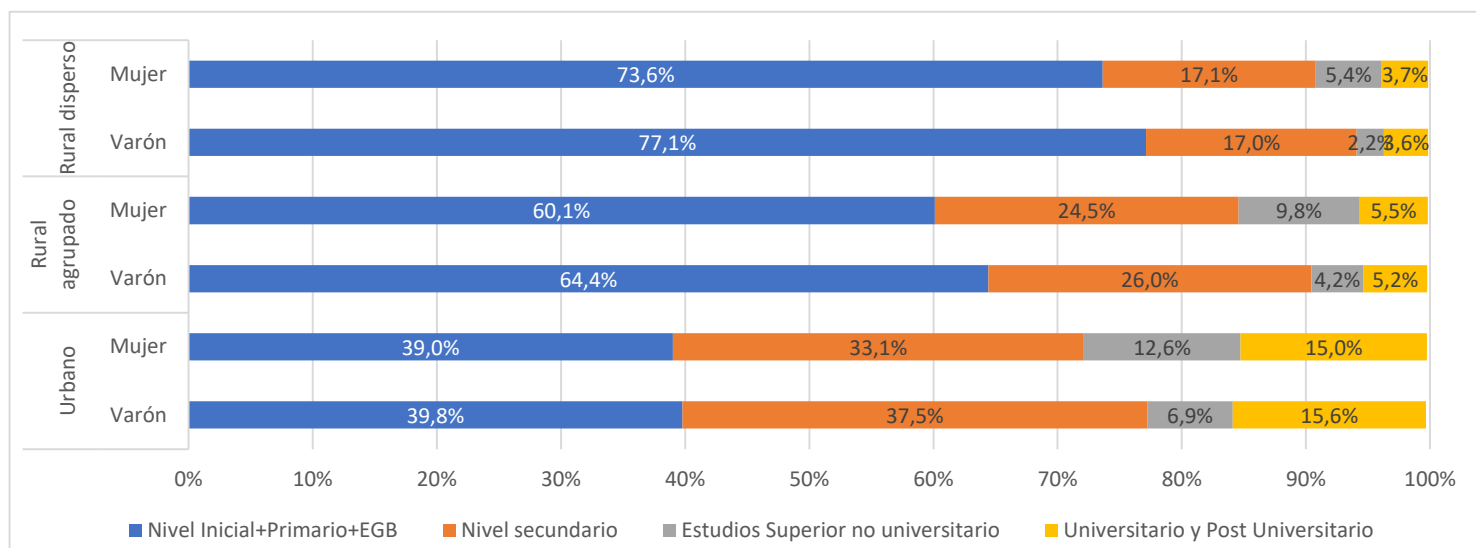

Fuente: Elaboración propia a partir de datos del INDEC. Censo Nacional de Población, Hogares y Viviendas 2010, procesado con Redatam+SP 
El análisis de género de esta información dice que, cuando existe posibilidades de continuar estudiando, las mujeres alcanzan más estudios que los varones en los distintos grupos residenciales, información que ya se evidenciaba en el 2001 (Biaggi, Canevari y Tasso, 2007). Se observa que en el área rural agrupada, un $24,5 \%$ de las mujeres terminaron el secundario y un $15,3 \%$ continuaron estudiando. En este mismo grupo residencial, un $26 \%$ de varones terminaron el secundario pero solo un 9,7\% siguió estudiando. En las áreas rurales dispersas, estos porcentajes son menores y son nuevamente las mujeres las que logran más estudios. En el caso específico de estudios superiores no universitarios, las mujeres se han orientado hacia carreras como la docencia, que son las que tienen mayores oportunidades laborales en el ámbito rural, y que muchas veces es la única opción de estudio en la localidad o departamento.

Es importante señalar que hay diferencias dentro del país y que los porcentajes de varones y mujeres que continúan estudiando varía entre las regiones y provincias. En todos los casos, se mantiene que las posibilidades de seguir estudiando son mayores en las áreas rurales agrupadas y también que las mujeres prolongan su etapa de estudios más que los varones. En la Región Pampeana, los porcentajes de población que continúa estudiando en las áreas rurales agrupadas son similares que en las áreas dispersas. En cambio, las provincias del NOA, NEA y Cuyo tienen porcentajes mayores en las localidades rurales, lo que indica las dificultades de las mujeres y varones que viven en el campo abierto para continuar los estudios finalizado el nivel primario. Misiones, Chaco y Santiago del Estero presentan los porcentajes más bajos de continuidad en el sistema educativo y La Rioja la mayor disparidad entre rural agrupado y disperso. En la Patagonia, Santa Cruz y Tierra del Fuego poseen mejores índices que sus provincias vecinas y también que en el resto del país.

Por lo descripto hasta acá es posible decir que:

a) hubo políticas públicas preocupadas en la educación rural y el mejoramiento de la infraestructura educativa en los últimos 20 años;

b) aunque con tendencias más positivas que en décadas anteriores, existe aún una brecha urbano-rural;

c) a mayor nivel de aislamiento es más difícil continuar con los estudios finalizada la escuela primaria;

d) existen diferencias entre los territorios, debido a especificidades económicas, sociales y geográficas y también de implementación de políticas específicas en cada una de las provincias;

e) hay un mayor nivel educativo de las mujeres respecto a los varones debido a cambios culturales y al comportamiento diferencial del mercado laboral.

Una problemática son las dificultades de acceso de los/as docentes a las escuelas rurales. Según el Relevamiento de Escuelas Rurales (RER) 2010, la mitad de las escuelas se encuentran en áreas rurales dispersas donde las vías de accesos a las mismas cobran relevancia en tanto brindan (o no) la posibilidad de que los alumnos/as y docentes puedan asistir en tiempo y forma a los establecimientos. En el documento de DiNIECE (2015) se muestra que solo en un poco más de la mitad de las escuelas rurales es posible llegar por medio de transporte de pasajeros que circule en forma regular (no esporádica) y que en la mayoría de los casos, cuando existe transporte es solo con una única frecuencia diaria.

Desde la perspectiva de los/as jóvenes, esta limitación histórica de falta de transporte regulares y caminos en mal estado se relaciona con las dificultades para mantener su residencia en las áreas rurales cuando quieren continuar sus estudios.

Sin dudas, el cambio fundamental en educación está marcado por el acceso a las nuevas tecnologías de información y comunicación (TIC). Antes de la llegada del COVID 19, las TICs ya habían delineado una nueva ruralidad en la cual se redujo la distancia entre la juventud rural y sus pares urbanos. La mayor conectividad fue factible por el acceso a sistemas de 
telecomunicación inalámbrica -teléfonos celulares- que proporcionaron una "infraestructura instantánea", sin necesidad de redes terrestres costosas (MAGyP, 2019).

El Censo 2010 cuantifica dos variables relacionadas a las TICs, el uso de computadoras y de telefonía celular. La información no muestra diferencias entre varones y mujeres ni por lugar de residencia con respecto a los teléfonos celulares. En el caso de las computadoras, tampoco hay diferencias significativas entre varones y mujeres pero si entre el ámbito rural y urbano; mientras que el $51 \%$ de la población urbana usaba computadora en el 2010, ese porcentaje disminuye a $32 \%$ en las áreas rurales agrupadas y a $16 \%$ en las dispersas. Sin embargo, hay una mínima diferencia favorable a las mujeres, algo mayor en la zona rural aislada, donde el $17 \%$ de las mujeres usan computadoras, contra el $15,6 \%$ de los hombres.

Aunque es muy pronto para evaluar las consecuencias del cambio en la educación hacia un modelo virtual, al menos temporariamente durante el 2020, hay indicios de que la falta de conectividad en muchas zonas rurales puede crear una nueva brecha con las ciudades. En un estudio realizado en abril del 2020 por Alejandro Artopoulos, del Observatorio Argentinos por la Educación, se observa que el 19,5\% del alumnado de escuelas primarias del país no tienen acceso a internet, pero hay grandes diferencias entre provincias. Por un lado, hay siete provincias donde al menos un tercio del alumnado no cuenta con internet en su hogar: $41 \%$ en Santiago del Estero; $38 \%$ en Formosa; 36\% en San Juan; 35\% en Catamarca, 35\% en Misiones; 34\% en Chaco y 33\% del alumnado de Corrientes no tienen internet. En el otro extremo, La Pampa, Tierra del Fuego y la Ciudad Autónoma de Buenos Aires solo menos de un 10\% del alumnado tiene problemas de conectividad.

En el nivel secundario, el porcentaje nacional desciende a 15,9\%, manteniéndose las diferencias regionales. Sin embargo, hay provincias con porcentajes mayores de jóvenes de nivel secundario con problemas de conectividad. Son Salta $(29,7 \%)$, Catamarca $(29,5 \%)$, Formosa $(29,5 \%)$, Misiones $(29,4 \%)$, Corrientes (28,9\%), Jujuy (28,7\%), San Juan (27,8\%), Santiago del Estero $(26,8 \%)$ y Chaco $(26,1 \%)$.

A pesar de que este estudio no indaga si la residencia es rural o urbana de quienes no tienen acceso, se observa que las provincias con mayores índices de ruralidad son las que poseen peores niveles de conectividad.

\section{LAS MUJERES RURALES Y EL TRABAJO REMUNERADO}

A continuación, se presenta un análisis de la información relacionada con la condición de ocupación y las categorías ocupacionales de la población rural del Censo 2010 para tener una primera aproximación de la relación de las mujeres con el trabajo remunerado, pero advirtiendo desde el principio que la misma tiene un sesgo hacia las mujeres trabajadoras rurales porque muchas de ellas se encuentran consideradas dentro de la categoría de inactivas.

\subsection{La condición de actividad de las mujeres rurales}

Existen tres categorías de ocupación para el INDEC: ocupado, desocupado e inactivo. La primera es para quienes trabajaron al menos una hora en la última semana, o no lo hicieron por estar de licencia. Desocupados son los/as que buscan o buscaron trabajo en el último mes. Los ocupados y desocupados conforman la población activa y los inactivos son las personas mayores de 14 años que no trabajaron ni una hora en la última semana ni buscaron trabajo en el último mes.

La asignación de la categoría ocupado se realiza en base a las siguientes preguntas: a) Durante la semana pasada, ¿trabajó por lo menos una hora? (sin contar las tareas de su hogar) y b) En esa semana, ¿̇hizo alguna changa, algo para vender afuera o ayudó a un familiar/ amigo en una chacra o negocio?

La forma en que el trabajo es visto tanto por los varones como por las mujeres en el ámbito rural contribuye a la escasa conciencia de que las tareas productivas a escala del predio constituyan 
una ocupación. Además, es parte de la problemática de género que las mujeres desvaloricen su trabajo, y esto es aún más significativo en el medio rural porque ese trabajo es realizado la mayor parte de las veces al mismo tiempo que las actividades de cuidado de la familia. Por lo tanto, las mujeres que tienen un huerto, animales o cualquier producción que permita la alimentación parcial o total del hogar, es probable que contesten "no" a las dos preguntas anteriores sobre la condición de actividad y, de esa manera, figuren en la categoría de "inactivas".

Lo mismo ocurre con otros trabajos característicos del sector informal rural -en algunos casos ejercidos bajo la forma del/a trabajador/a cuenta propia, como el trabajo artesanal-que tampoco son considerados ni por las propias mujeres como ocupación (Biaggi, Canevari y Tasso, 2007). Son actividades productivas generadoras de renta familiar que se venden en momentos determinados del año o por encargo; por ejemplo, las productoras hilan y tejen prendas de vestir o elaboran quesos, dulces, conservas para ferias, mercados o tiendas que comercializan productos de la agricultura familiar.

La condición de desocupado/a se mide a partir de una pregunta sobre la búsqueda de trabajo en el último mes. Las oportunidades de los sectores rurales de buscar trabajo son ciertamente bajas y aún más para las mujeres. Ante la dificultad de encontrar trabajo, muchas veces las mujeres no "están buscando", lo cual no significa que no lo quieran hacer, sino que los caminos de búsqueda son diferentes (por ejemplo, esperar que llegue la época de la cosecha o alguna demanda específica en la zona).

Por lo tanto, hay un sobre registro de la categoría inactiva y un sub registro de la población económicamente activa porque los instrumentos para la medición de la condición de ocupación son inadecuados para captar el trabajo que realizan las mujeres en las áreas rurales. Es atinada la pregunta que Silvina Alegre (2015) realiza cuando cuestiona el indicador "tasa de actividad" en su análisis de los datos del INDEC: "¿Alguien podría sostener, desde el más básico sentido común, que las mujeres que viven en el campo son en su mayoría (54,4\% en el censo 2001) "inactivas"?"

Lo anterior queda visibilizado al analizar la información del Censo 2010 que muestra grandes diferencias de condición de actividad según la zona de residencia urbana o rural, pero mucho más cuando el análisis se hace por sexo. En promedio para todo el país, el $73 \%$ de los varones y el $48 \%$ de las mujeres se definen como ocupados/as mientras que el $3 \%$ y $4 \%$ respectivamente como desocupados. La población inactiva representa al $24 \%$ de varones y $48 \%$ de mujeres. Los mayores porcentajes de inactivo/a se alcanzan dentro de la población rural, y el más alto se encuentra en las mujeres del campo profundo, donde llega al 65\%.

Comparando estos porcentajes con los obtenidos en el censo anterior, hubo una disminución de las tasas de desocupación entre 2001 y 2010, probablemente porque los valores del 2001 estuvieron afectados por la crisis económica que vivió el país en ese año. A nivel nacional, el índice de ocupación de varones en el año 2001 era de 53\%, y de mujeres, 30\%; había un 17\% de varones desocupados y un $15 \%$ de mujeres desocupadas, mientras que el índice de inactividad era de $29 \%$ y 55\%, encontrando los mayores porcentajes de inactividad en la población femenina rural de zonas aisladas (INDEC, 2021). Es importante señalar que estos datos muestran que el cambio de población económicamente activa entre 2001 y 2010 no fue importante, sino que disminuyó la desocupación y que la cantidad de población inactiva se sostuvo a lo largo del tiempo. Con respecto a las mujeres, se observa un crecimiento de la ocupación, aunque menos que la población total.

La figura siguiente muestra la información presentada en el párrafo anterior. Es posible ver que las diferencias entre mujeres y varones se encuentran principalmente en la categoría ocupado e inactivo en el 2001 y en el 2010. 
Figura 10 Porcentaje de población ocupada, desocupada e inactiva mayor de 14 años por sexo según lugar de residencia años 2001 y 2010.

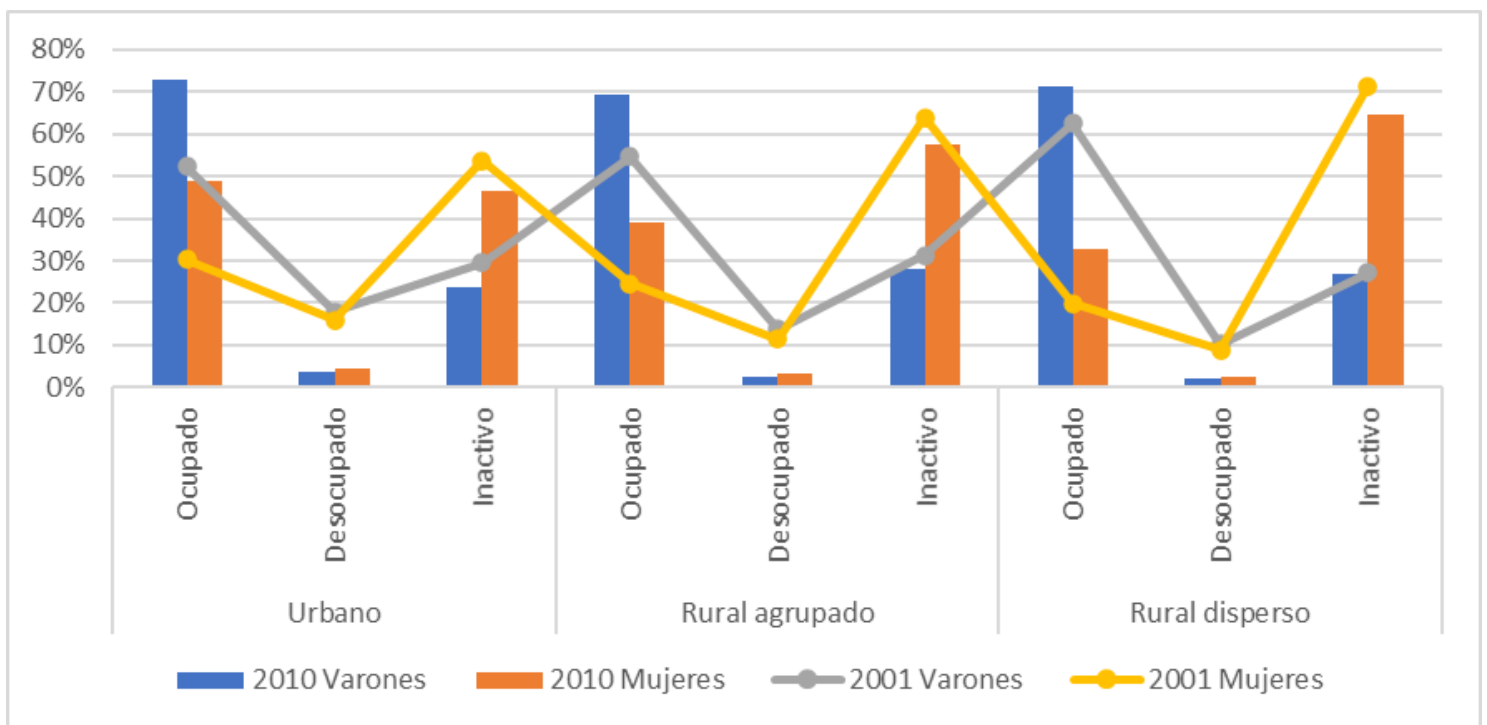

Fuente: Elaboración propia a partir de datos del INDEC. Censo Nacional de Población, Hogares y Viviendas 2001 y 2010, procesado con Redatam+SP

En el 2010, el $27 \%$ de las mujeres que residen en las áreas rurales aisladas del norte de Argentina se presentan como ocupadas y el $70 \%$ como inactivas (con valores extremos de $76 \%$ en Santiago del Estero y Corrientes). Diferente es en la Región Pampeana, donde esos porcentajes son de $41 \%$ y $56 \%$ para las mujeres ocupadas e inactivas en las áreas rurales dispersas, y en la Patagonia de $47 \%$ y $50 \%$. Por lo tanto, no es posible hablar de la situación ocupacional de las mujeres rurales sin identificar, además de las brechas de género, las brechas geográficas que se explicitan la realidad económica y social en cada de una de las regiones y provincias (Alegre, 2015).

Como se dijo anteriormente, la categoría de inactivas incluye a una gran cantidad de mujeres que carecen de un ingreso monetario por los trabajos que realizan en el predio, que muchas veces aseguran la alimentación del grupo familiar, y en ocasiones es suficiente para resolver cuestiones ligadas a la pobreza. En estos hogares, el censo identifica a los varones en la categoría de ocupado $y$, salvo que las mujeres indiquen lo contrario, no reconoce como trabajo a las actividades de producción de alimentos para el consumo familiar ni la realización de tejidos, cestería, alfarería, etc.

La discusión de la incidencia del trabajo no remunerado está en la agenda actual del INDEC, con la propuesta de utilizar encuestas de uso del tiempo para la medición de una de las formas de desigualdad más extendida entre varones y mujeres: la participación y el tiempo dedicado al trabajo no remunerado y a las actividades de cuidado. La encuesta de uso del tiempo permite hacer visible lo invisible, jerarquizar tareas y echar luz sobre la desigualdad en la distribución de estas tareas cotidianas y en la intensidad con que distintas personas las abordan (INDEC, 2020). Sin embargo, será necesario considerar e identificar las especificidades rurales que son significativas. En ese aspecto, hay aportes en la trayectoria del trabajo con mujeres rurales desde el Ministerio de Agricultura que por medio de los presupuestos de tiempo contribuyeron al reconocimiento de las desigualdades de género naturalizadas social y culturalmente y la mayor carga horaria de las mujeres en las localidades donde se implementó el proyecto Mujer Rural de NOA (Álvarez et al., 1992; Aradas, 2013).

\subsection{Las relaciones laborales}


La población ocupada, que para el censo está conformada principalmente por aquella que recibe un salario a cambio de su trabajo, es agrupada por el INDEC en cuatro categorías: obrero/a o empleado/a, patrón/a, cuentapropista y trabajador/a familiar.

Tabla 3 Cantidad y porcentaje de varones y mujeres y cantidad y porcentaje de la población total mayor de 14 años según categoría ocupacional y lugar de residencia

\begin{tabular}{|c|c|c|c|c|c|c|c|}
\hline $\begin{array}{l}\text { Lugar de } \\
\text { residencia }\end{array}$ & \multirow{2}{*}{$\begin{array}{l}\text { Categoría ocupacional } \\
\text { Obrero o empleado/a }\end{array}$} & \multicolumn{2}{|c|}{$\begin{array}{c}\text { Cantidad y \% de } \\
\text { varones }\end{array}$} & \multicolumn{2}{|c|}{$\begin{array}{c}\text { Cantidad y \% de } \\
\text { mujeres }\end{array}$} & \multicolumn{2}{|c|}{$\begin{array}{l}\text { Cantidad y \% de la } \\
\text { población total }\end{array}$} \\
\hline \multirow{5}{*}{$\begin{array}{l}\text { Area } \\
\text { urbana }\end{array}$} & & 6.711 .700 & $70,3 \%$ & 5.172 .855 & $72,6 \%$ & 11.884 .555 & $71,3 \%$ \\
\hline & Patrón/a & 735.851 & $7,7 \%$ & 404.864 & $5,7 \%$ & 1.140 .715 & $6,8 \%$ \\
\hline & Cuentapropista & 1.871 .657 & $19,6 \%$ & 1.296 .853 & $18,2 \%$ & 3.168 .510 & $19,0 \%$ \\
\hline & Trabajador/a familiar & 233.281 & $2,4 \%$ & 252.019 & $3,5 \%$ & 485.300 & $2,9 \%$ \\
\hline & Total & 9.552 .489 & $100 \%$ & 7.126 .591 & $100 \%$ & 16.679 .080 & $100,0 \%$ \\
\hline \multirow{5}{*}{$\begin{array}{l}\text { Area rural } \\
\text { agrupado }\end{array}$} & Obrero o empleado/a & 232.196 & $71,0 \%$ & 134.964 & $73,0 \%$ & 367.160 & $71,8 \%$ \\
\hline & Patrón/a & 24.225 & $7,4 \%$ & 10.758 & $5,8 \%$ & 34.983 & $6,8 \%$ \\
\hline & Cuentapropista & 59.056 & $18,1 \%$ & 30.318 & $16,4 \%$ & 89.374 & $17,5 \%$ \\
\hline & Trabajador/a familiar & 11.359 & $3,5 \%$ & 8.730 & $4,7 \%$ & 20.089 & $3,9 \%$ \\
\hline & Total & 326.836 & $100 \%$ & 184.770 & $100 \%$ & 511.606 & $100,0 \%$ \\
\hline \multirow{5}{*}{$\begin{array}{l}\text { Area rural } \\
\text { disperso }\end{array}$} & Obrero o empleado/a & 424.425 & $66,3 \%$ & 157.120 & $63,9 \%$ & 581.545 & $65,6 \%$ \\
\hline & Patrón/a & 40.388 & $6,3 \%$ & 11.815 & $4,8 \%$ & 52.203 & $5,9 \%$ \\
\hline & Cuentapropista & 130.234 & $20,3 \%$ & 49.430 & $20,1 \%$ & 179.664 & $20,3 \%$ \\
\hline & Trabajador/a familiar & 45.230 & $7,1 \%$ & 27.451 & $11,2 \%$ & 72.681 & $8,2 \%$ \\
\hline & Total & 640.277 & $100 \%$ & 245.816 & $100 \%$ & 886.093 & $100,0 \%$ \\
\hline
\end{tabular}

Fuente: Elaboración propia a partir de datos del INDEC. Censo Nacional de Población, Hogares y Viviendas 2010, procesado con Redatam+SP

En cada categoría, casi siempre hay más varones que mujeres y estas diferencias se acentúan en las zonas rurales, encontrando la mayor disparidad en las áreas rurales dispersas con diferencias significativas entre los territorios.

En la Patagonia hay un incremento, en comparación a la media nacional, de la proporción de la categoría obrero/a o empleado/a especialmente en las pequeñas localidades, y bajos porcentajes en cuentapropistas, sobre todo para las mujeres en las áreas rurales dispersas. Ocurre lo contrario en las provincias del NEA, donde los porcentajes de la categoría obrero/a o empleado/a son menores que a nivel nacional tanto para los varones como para las mujeres que viven en el campo y aumentan los/as cuentapropistas, llegando al $29 \%$ en la zona rural dispersa (incluso superándolo en Formosa y Misiones).

La categoría trabajo familiar incluye a quienes realizaron tareas regulares de ayuda en la actividad de un familiar, reciban o no una remuneración por ello. Presenta mayores proporciones en las áreas rurales que en las ciudades, especialmente en el sector rural aislado y en las mujeres $(11,2 \%)$. Los valores más altos se alcanzan en el NEA, con un $24 \%$ para las mujeres y $14 \%$ para los varones del campo profundo (en Misiones, $34 \%$ de las mujeres y $21 \%$ de los varones). En contraposición, los valores más bajos de esta categoría están en las áreas rurales agrupadas de Cuyo. Probablemente, muchas de las mujeres relevadas como inactivas deberían estar en la categoría de trabajadora familiar.

Como indicador del desbalance de poder entre mujeres y varones, es en la categoría patrón/a que muestra la tabla anterior donde hay una mayor diferencia entre géneros, tanto en las ciudades como en las áreas rurales. Sin embargo, los porcentajes son bajos en casi todas las provincias con excepción de la Región Pampeana (12\% de varones y $8 \%$ de mujeres en las zonas rurales).

\subsection{Las ocupaciones de las mujeres}


Otra caracterización que realiza el Censo 2010 es por el tipo de trabajo de la población activa, agrupando a la misma en 27 diferentes categorías. A partir del análisis de las mismas se observa que en las áreas urbanas, las principales ocupaciones de las mujeres son: 17\% en gestión administrativa, jurídica, contable y financiera; $17 \%$ en limpieza doméstica y no doméstica; $12 \%$ en educación y $11 \%$ en comercialización. Los varones de las ciudades tienen como principales ocupaciones construcción (16\%), producción industrial y artesanal (11\%), gestión administrativa (11\%) y comercialización (11\%). Por lo tanto, en comercio no hay diferencias entre sexos, pero en las tareas de limpieza predominan las mujeres y en construcción, los varones. Aunque es baja la proporción de personas en funciones directivas y gerenciales, tanto en las empresas grandes como en las pequeñas, hay casi el doble de varones que de mujeres en ese tipo de ocupación.

En las áreas rurales agrupadas, el $21 \%$ de las mujeres están ocupadas en tareas de limpieza, además de un $13 \%$ en educación y un $12 \%$ en gestión administrativa. Los varones de las pequeñas localidades rurales tienen como principal ocupación la producción agrícola (16\%) y la construcción (15\%). En campo abierto o rural disperso, las principales ocupaciones de las mujeres son limpieza (17\%) y producción agrícola (16\%), además de un $8 \%$ que es docente mientras que casi la mitad de los varones están ocupados en actividades agrícolas o ganaderas. En cuanto al acceso a cargos jerárquicos, nuevamente las mujeres son menos que los varones, y en forma más acentuada que en las ciudades, siendo menos de la tercera parte las mujeres que los varones. Nuevamente, la baja proporción de mujeres en actividades agropecuarias refuerza el planteo del subregistro, ya que la mayoría de las que figuran como inactivas son quienes se dedican principalmente a estas producciones.

Tabla 4 Gráfico resumen de las principales ocupaciones de la población activa por lugar de residencia y sexo

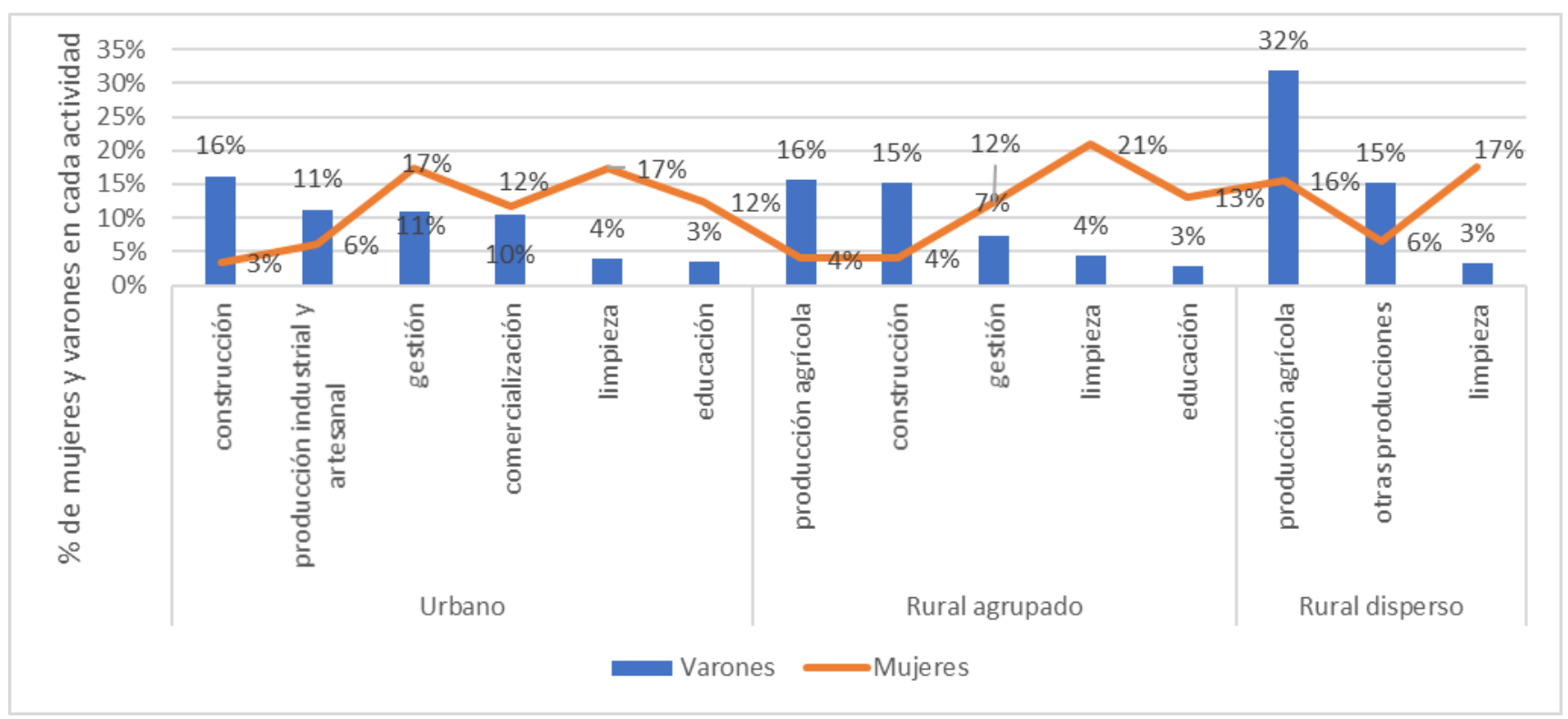

Fuente: Fuente: Elaboración propia a partir de datos del INDEC. Censo Nacional de Población, Hogares y Viviendas 2001 y 2010, procesado con Redatam+SP

Es interesante encontrar que las mujeres tienen porcentajes importantes tanto en las áreas urbanas como en las pequeñas localidades rurales en las ocupaciones de la gestión administrativa, jurídica, contable y financiera. Ejemplos de este tipo de ocupación son secretarias, información al público; recibir, distribuir y despachar documentación; administración de un local, etc. (INDEC, 2021). 
Como comentarios finales es bueno señalar que:

- El acceso de las mujeres a los trabajos asalariados es una de las principales limitantes para la equidad y es donde se visibiliza especialmente la brecha de género existente en nuestras sociedades. Los instrumentos de registro utilizados en los censos poblacionales para conocer la condición de actividad de las mujeres refuerzan esta inequidad cuando son insuficientes para reconocer los trabajos de las mujeres dentro del predio y, por lo tanto, categorizarlas como inactivas junto a los/as jubilados/as y enfermos/as.

- Cuando las mujeres acceden a una remuneración por su trabajo, el tipo de actividad que realizan depende de la región donde residan porque las opciones son diferentes en las distintas provincias. En las zonas con más población rural, hay más cuentapropistas y las mujeres aparecen en la categoría de trabajadora familiar, porque el censo considera la realización de tareas regulares de ayuda en la actividad familiar. Sin embargo, en algunas provincias se evidencia en el análisis del censo un sub registro de mujeres en la categoría de trabajadora familiar.

- Es imposible no mencionar la importancia de las mujeres en las ocupaciones de limpieza tanto en las áreas urbanas como rurales, que es un trabajo culturalmente asignado a las mujeres como una continuidad de sus quehaceres de cuidado y que las coloca en una posición subalterna en nuestra sociedad. Las mujeres también aparecen en ocupaciones de educación en proporciones mayores que los varones.

- Otro rubro en el que prevalecen las mujeres es en las tareas directivas del Estado y de Organizaciones de la sociedad civil. Si bien este rubro cobra mayor significación en las ciudades, en todas las zonas se observa algún predominio femenino. Esto se debe al peso relativo de las organizaciones de la sociedad civil, vinculadas en muchos casos a actividades de índole social o educativo (bibliotecas, fundaciones, etc.), trabajos que, como en el rubro anterior, históricamente fueron considerados una continuidad de las tareas de cuidado y, por ende, de mujeres.

\section{LAS MUJERES RURALES CON NECESIDADES BÁSICAS INSATISFECHAS (NBI)}

La pobreza estructural es una de las razones más importantes de la migración del campo a la ciudad, y aunque afecta tanto a varones como a mujeres, se experimenta de manera distinta según el sexo y la edad, además del grupo étnico y del rol dentro de la familia. Las desigualdades de género respaldan la aseveración de que la pobreza femenina no puede comprenderse bajo el mismo enfoque que la pobreza masculina (Kabeer, 1994).

Los varones y las mujeres sufren de diferente manera la pobreza porque tienen desigual acceso a los recursos y al empleo y porque subsisten relaciones de poder asimétricas. La primera diferencia que expone a las mujeres a una mayor desventaja y fragilidad en contextos de pobreza es su responsabilidad ante el cuidado de la familia. A pesar de los cambios actuales, la división del trabajo en los hogares sigue siendo rígida y son las mujeres las que enfrentan en el cotidiano las dificultades de acceso a los servicios de salud y continúan siendo las principales responsables de la seguridad alimentaria en los hogares. Esto se agudiza cuando el Estado tiene menor presencia, como ocurre en el sector rural.

En América Latina existen altos índices de pobreza, encontrándose brechas muy significativas entre los territorios urbanos y rurales. En Argentina, al igual que en otros países del continente, una forma de medir la pobreza es por medio del índice de Necesidades Básicas Insatisfechas. El NBI identifica las condiciones de pobreza más allá de la insuficiencia de ingresos, apuntando a la misma como el resultado de un cúmulo de privaciones materiales esenciales. La definición de pobreza mediante este enfoque tiene la ventaja de que se aplica una metodología multidimensional para la medición directa de las condiciones de vida, que permite analizar su evolución en el largo plazo sin recurrir a los ingresos de los hogares. 
Se considera que un hogar es pobre por NBI si sufre al menos alguna de las siguientes carencias o privaciones: vivienda de tipo inconveniente; viviendas sin cuarto de baño; hacinamiento crítico (más de tres personas por cuarto); hogares con niños en edad escolar que no asisten a la escuela; y hogares con cuatro o más personas por miembro ocupado y en los cuales el/la jefe/a de hogar tiene bajo nivel de educación (dos años o menos en el nivel primario).

A los fines de este estudio, es un instrumento que permite desagregar geográficamente las zonas donde hay población rural en situación de pobreza. Sin embargo, como el NBI tiene al hogar como unidad de análisis, no posibilita identificar diferencias significativas entre mujeres y varones por lo que los porcentajes de población rural femenina y masculina con NBI son muy similares. Desde la perspectiva de género, que el NBI explique la pobreza por carencias habitacionales alerta sobre las condiciones donde las mujeres desarrollan las responsabilidades asignadas del cuidado del grupo familiar, que están vinculadas directamente con las condiciones de las viviendas donde cumplen sus tareas y donde pasan la mayor parte de su tiempo. Por otro lado, y como ocurre con otros indicadores, describe situaciones extremas con una clasificación dicotómica (pobre-no pobre) y no permite una diferenciación en su interior.

A partir del Censo 2010, se sabe que un 16,2\% de las mujeres que residen en áreas rurales agrupadas tienen por lo menos una necesidad básica insatisfecha y en las áreas rurales dispersas ese porcentaje aumenta a 26,8\%. En el caso de los varones, como ya se dijo, los porcentajes son muy similares al de las mujeres: un 16,7\% de varones con NBI en las áreas rurales agrupadas y un $26,8 \%$ en las dispersas. La condición de pobreza de las mujeres y varones que residen en las ciudades es significativamente menor que la de la población rural, ya que son $11,4 \%$ y $12,1 \%$ respectivamente.

Estos porcentajes indican que la pobreza estructural, medida con los indicadores de NBI, está asociada con la condición de ruralidad, donde las características de la vivienda y la falta de retretes influyen considerablemente en estos mayores niveles de NBI. Esta situación de exclusión y "de atraso" se mantiene, pese a diversas iniciativas para promover la retención de los/as habitantes rurales. Las diferencias regionales se pueden observar en la figura siguiente.

Figura 11 Porcentaje de mujeres rurales con NBI según lugar de residencia por región y provincia

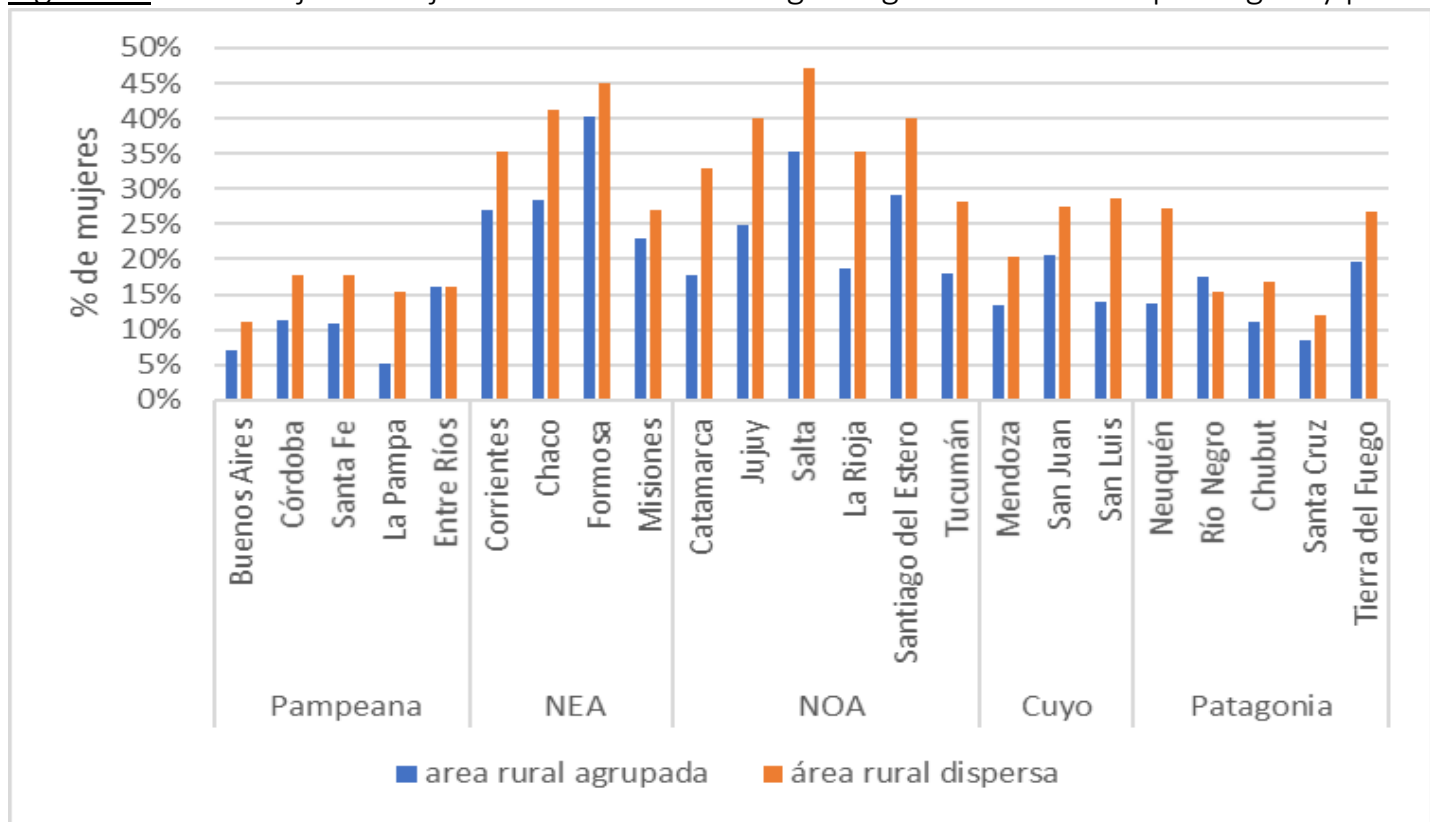

Fuente: Fuente: Elaboración propia a partir de datos del INDEC. Censo Nacional de Población, Hogares y Viviendas 2001 y 2010, procesado con Redatam+SP

La figura anterior muestra que son mayores los porcentajes de mujeres rurales en situación de necesidades básicas insatisfechas (NBI) en las áreas rurales dispersas y en las provincias del norte 
del país, donde los valores son del $45 \%$ en Formosa y del $47 \%$ en Salta. En las zonas agrupadas del NOA y del NEA, los niveles de pobreza se ubican entre el $18 \%$ y $40 \%$.

En comparación al Censo 2001, los porcentajes de mujeres en condiciones de NBI en las áreas rurales disminuyó en todas las provincias, aunque se mantienen alto en las provincias del NOA, NEA y Cuyo. En el año 2001, las regiones del NEA y NOA presentaban porcentajes de población rural con NBI cercanos a la mitad de la población de estas regiones y una década después, disminuyó aproximadamente a una tercera parte.

Figura 12 Porcentajes de mujeres que residen en las áreas rurales dispersas con NBI en las diferentes provincias en los Censos 2001 y 2010

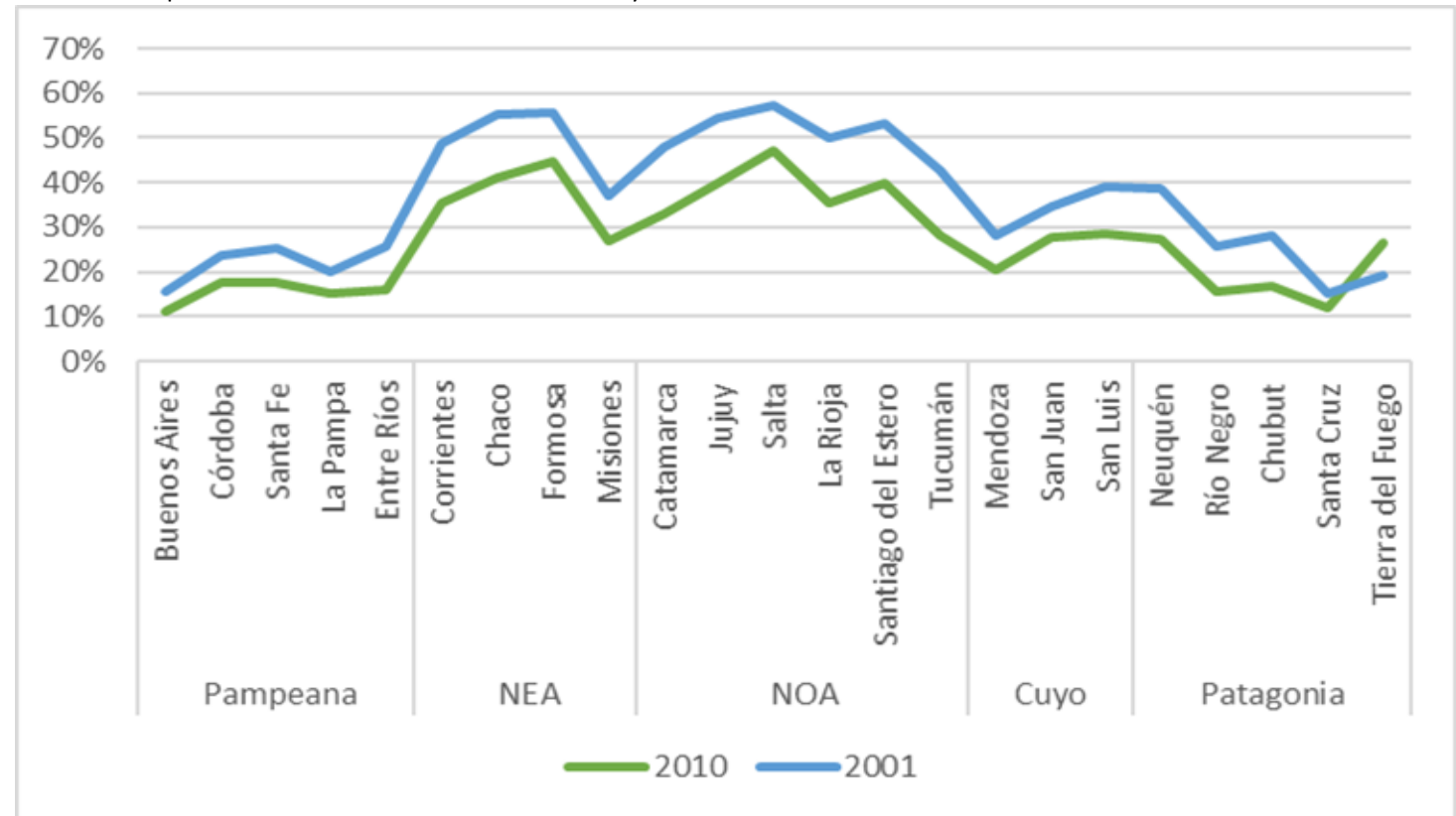

Fuente: Fuente: Elaboración propia a partir de datos del INDEC. Censo Nacional de Población, Hogares y Viviendas 2001 y 2010, procesado con Redatam+SP

El indicador NBI presenta falencias para la discusión de pobreza y género. La falta de medición de las posibilidades de acceso a los servicios de transporte $y$, principalmente, de salud es una limitante sustancial para el análisis de equidad de género. Cuando las mujeres no tienen acceso a la salud, la situación de pobreza se proyecta sobre ella y los/as integrantes de las familias que, en general, son numerosos/as porque las zonas donde hay población de mujeres con NBI coincide con las regiones donde hay una mayor cantidad de hijos por mujer. Cuando los centros de salud tienen difícil acceso o se encuentran en las ciudades, las mujeres destinan gran cantidad de recursos y tiempo para el cuidado de sus hijos/as pequeños/as y de otros/as integrantes de la familia que necesitan atención médica, además de situaciones de discriminación por pautas culturales que desconocen la diversidad entre lo rural y urbano. Existe una invisibilización de esta situación porque son las mujeres las responsables dentro de la familia de las tareas de cuidado, las cuales son menos jerarquizadas que los trabajos remunerados.

\section{LAS MUJERES RURALES JEFAS DE HOGAR}

En las áreas rurales, las mujeres son jefas de hogar cuando no hay un varón en la casa, lo cual ocurre generalmente por migración definitiva o fallecimiento. Si en la finca, el varón migró en forma temporal o es una persona de mucha edad, en general se sigue considerando que la mujer no es la jefa del hogar, aunque sea la principal responsable del sistema productivo. Esto se sostiene por la existencia de una división de roles y mandatos no explícitos dentro de las familias que configuran como las mujeres y los otros integrantes perciben la jefatura del hogar, más allá de la contribución de las mujeres en el trabajo, de sus aportes económicos y de su participación en la 
toma de decisiones. Además, el censo da la opción de un solo jefe y de un cónyuge, y esto casi determina la opción posible, el varón es el jefe y la mujer el cónyuge (salvo excepciones).

Cuando la jefatura de los hogares es femenina, existe una mayor fragilidad económica y social del grupo familiar. Esto se debe a que, por su condición simultánea de responsables de la reproducción del grupo doméstico y de productoras, las mujeres no siempre pueden cultivar toda la tierra disponible u ocuparse de las actividades generadoras de ingresos (Biaggi, Canevari y Tasso, 2007; Biaggi, 2008). Además, tienen escasa o nula experiencia en gestión, al mismo tiempo que dificultades para acceder a los servicios de extensión y crédito (Biaggi, 2018).

El Censo 2010 muestra que, en las áreas urbanas, los porcentajes de mujeres jefas de hogar son mayores que en el campo y tanto en las ciudades como en las áreas rurales, hay un aumento de mujeres jefas de hogar entre el 2001 y 2010. Las diferencias censales pueden deberse a un mayor avance en la conquista de derechos de las mujeres en las ciudades respecto al campo (es decir, no están tan condicionadas al responder); a la existencia de más familias monomarentales o una conjunción de ambos procesos.

Figura 13 Porcentajes de mujeres y varones de las áreas rurales que son jefes/as de hogar en las diferentes provincias en los Censos 2001 y 2010

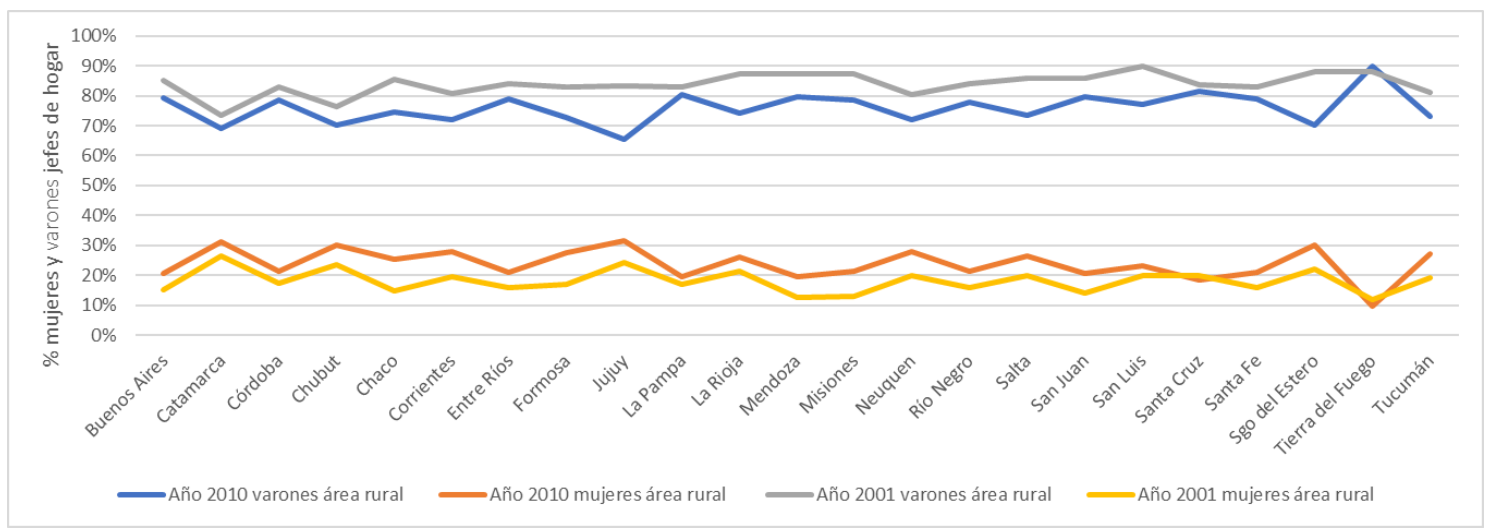

Fuente: Fuente: Elaboración propia a partir de datos del INDEC. Censo Nacional de Población, Hogares y Viviendas 2001 y 2010, procesado con Redatam+SP

Como muestra el gráfico anterior, las mujeres rurales que se declaraban jefas de hogar en el año 2001 no alcanzaban el 30\% en ninguna de las provincias y el promedio para todo el país era de 17\%. El mayor porcentaje se encontraba en la provincia de Catamarca, con un $26 \%$ de mujeres jefas de hogar. Diez años después, las provincias donde se registran los mayores incrementos de mujeres jefas de hogar son Formosa, Chaco, Santiago del Estero, Corrientes, Misiones y Tucumán, aunque solo Jujuy y Catamarca superan ese $30 \%$. Como con otros análisis ya realizados, cuando la información del Censo 2010 se discrimina en áreas rurales agrupadas y dispersas, las zonas más alejadas y con población dispersa tienen porcentajes de jefatura femenina menores que en las pequeñas localidades rurales.

No es posible por medio del Censo 2010 conocer las razones de este aumento de la jefatura femenina en las áreas rurales. Silvina Alegre (2015) dice que puede estar explicado por el aumento de las separaciones y de la existencia de madres solteras. La Asignación Universal por Hijo (AUH) también aportó a que una parte de las mujeres que la reciben hayan modificado su autopercepción dentro de la familia, porque en algunos casos los montos que cobran son relativamente importantes e influyen para el sostenimiento del hogar, y las mujeres tienen muchas posibilidades de decidir en qué gastar ese dinero. En el libro de "Las nuevas generaciones de mujeres rurales como promotoras del cambio" (2015), hay testimonios que remarcan el uso de este dinero para la alimentación de los hijos/as y en su educación, además de implementos para mejorar las actividades domésticas, y muestran procesos individuales y grupales de empoderamiento de las mujeres que redundan en mejoras en la calidad de vida de los/as hijos/as. La posibilidad de contar 
con este recurso posibilitó que muchas mujeres víctimas de violencia pudieran salir de ese sitio y formar un nuevo hogar, bajo su propia jefatura.

Finalmente, dentro del nuevo paradigma de equidad de género que la sociedad está viviendo, eliminar la figura de jefe de hogar es casi imprescindible. Además de que invisibiliza a las mujeres y desconoce la cogestión del hogar, especialmente en el caso de las explotaciones agropecuarias, construye un orden jerárquico y de poder que no coincide con la búsqueda de relaciones de género equitativas.

\section{CONCLUSIONES}

En el 2010, la población del país era de 40.117 .096 de personas, y en el sector rural vivían el 9\% de ese total. De estas 3.600.000 personas que residían en las áreas rurales, solo el $46 \%$ eran mujeres porque, en el proceso de dejar el campo, han sido las mujeres quienes lo han hecho en mayor proporción. Esta migración femenina está vinculada con la disminución de la cantidad de explotaciones agropecuarias (EAPs) de las últimas décadas, que tuvo como principal consecuencia una menor cantidad de familias en la gestión productiva agraria. Desde la perspectiva de género, el proceso de concentración de la tierra significó una disminución de mujeres en trabajos tradicionalmente femeninos y la presencia cada vez mayor de varones solos en el campo, lo que no es un indicador positivo para el arraigo rural.

Por otro lado, la situación de desventaja en la que viven muchas mujeres rurales -permanencia de roles asignados culturalmente, sociedades más patriarcales que en las ciudades, aislamiento con débiles redes sociales, pocas opciones de ocio, deficientes infraestructuras y servicios de salud y un casi inexistente apoyo ante situaciones de violencia, que en algunos casos puede expresarse en una maternidad temprana- son un impulso para que las mujeres consideren que la ciudad puede ser un lugar con mejores posibilidades.

Un porcentaje de mujeres se mudan a localidades cercanas para que sus hijos/as puedan estudiar y porque las ciudades siguen siendo atractivas para la juventud. Además, en la ruralidad las prácticas de las personas son inscriptas con más fuerza según estereotipos de género y normas de conducta heterosexual, y cuando lo/as jóvenes no cumplen las expectativas y no se acomodan a la comunidad, hay una tendencia a la emigración.

Además de la menor presencia de familias en las áreas rurales, el bajo porcentaje de población rural se relaciona también con menores tasas de natalidad. Sin embargo, la maternidad temprana mantiene valores altos, especialmente entre las jóvenes que viven en zonas aisladas, comprometiendo las trayectorias de vida de las mismas.

Con respecto a la educación, las políticas públicas de mejoramiento de la infraestructura y recursos humanos en educación rural de los últimos 20 años se traducen en una asistencia cercana del $100 \%$ a escuelas primarias en las áreas rurales. En el período 2001-2010, en los establecimientos secundarios rurales, hubo un aumento del nivel de asistencia escolar y una disminución del abandono escolar. La tasa de analfabetismo en el 2010 es cercana al 99\%. Sin embargo, la población rural, y especialmente la que vive en territorios más aislados, sigue siendo postergada en el acceso a educación finalizado el ciclo inicial, lo que vulnera la igualdad de oportunidades. Desde una perspectiva de género, las mujeres rurales alcanzan un mayor nivel educativo en comparación a los varones, debido tanto a cambios culturales; pero también porque al tener más dificultades de inserción laboral, las jóvenes expresan la voluntad y la necesidad de seguir estudiando.

Un cambio fundamental en educación está marcado por el acceso a las nuevas tecnologías de información y comunicación (TIC). Antes de la llegada del COVID 19, las TICs ya delinearon una nueva ruralidad en la cual se redujo la distancia entre la juventud rural y sus pares urbanos. La mayor conectividad fue factible por el acceso a tecnologías tales como los satélites y los sistemas de telefonía celular, que proporcionaron una "infraestructura instantánea", sin necesidad de 
redes terrestres costosas. La pandemia está acelerando estos cambios y se conforma un nuevo paradigma en las áreas rurales, aunque la falta de conectividad en muchas zonas puede crear una nueva brecha con las ciudades.

Respecto al trabajo, la categoría población activa en las áreas rurales tiene un sesgo de subregistro por estar efectuada con instrumentos de medición inadecuados para captar principalmente tanto el trabajo de las mujeres, en especial los realizados en la explotación agropecuaria familiar, como por las posibilidades reales de búsqueda de trabajo para mujeres y para varones. Por esta razón, la información del Censo 2010 muestra grandes diferencias de condición de actividad según la zona de residencia y mucho más por sexo.

El concepto de trabajo es una categoría histórica, construida en respuesta a necesidades de una época determinada y su significado ha ido variando a lo largo del tiempo. Este concepto está vinculado casi exclusivamente a la realización de actividades productivas ligadas al mercado, pero en realidad el trabajo mercantil constituye solo una parte del trabajo productivo. Desde hace varios años, el trabajo doméstico y de cuidado no remunerado se reconoce como un trabajo cuyo objetivo es proveer servicios para los miembros de la familia y de la comunidad (INDEC, 2020). Es necesario avanzar en la identificación del trabajo no remunerado y de cuidado, como trabajo con valor económico, lo que a su vez refuerza la necesidad de visibilizarlo y cuantificarlo a través de una encuesta nacional de uso del tiempo. Para esto, será necesario identificar y considerar las especificidades rurales, para tener en cuenta la cantidad y variedad de las actividades que hacen las mujeres.

En el análisis de pobreza se observa que los varones y las mujeres sufren de diferente manera la pobreza porque tienen desigual acceso a los recursos y al empleo, y porque subsisten relaciones de poder asimétricas. A pesar de los avances, la división del trabajo en los hogares sigue siendo rígida y son las mujeres las que enfrentan las dificultades de acceso a los servicios de salud y continúan siendo las principales responsables de la seguridad alimentaria. Esto se agudiza cuando el Estado tiene menor presencia, como en el sector rural.

Este recorrido del Censo 2010 muestra la necesidad de modificar las preguntas para abarcar mejor las cuestiones de género y la manera en que se realizan las preguntas, porque el qué se pregunta es tan importante como el cómo. Un tema probablemente más difícil de revertir y que implica un desafío, es la mirada binaria que atraviesa toda la estadística.

Aún con las limitaciones que puede significar mirar el mundo rural a partir de números, queda claro la necesidad de pensar políticas públicas integrales que equiparen la calidad de vida de mujeres y varones con más acceso a la salud, a la educación secundaria y terciaria, a las nuevas tecnologías y sobre todo a trabajo y vivienda en condiciones dignas. Además, se necesitan estrategias orientadas a los/as jóvenes, pensando el desarrollo de políticas de arraigo con perspectiva de género. 


\section{ANEXOS}

ANEXO 1. Cantidad de población urbana y población rural agrupada y rural dispersa discriminada por sexo según provincia

\begin{tabular}{|c|c|c|c|c|c|c|c|}
\hline \multirow{3}{*}{ Provincia } & \multirow{2}{*}{\multicolumn{2}{|c|}{ Población urbana }} & \multicolumn{4}{|c|}{ Población rural } & \multirow{3}{*}{ Total } \\
\hline & & & \multicolumn{2}{|c|}{ Rural agrupada } & \multicolumn{2}{|c|}{ Rural dispersa } & \\
\hline & Varones & Mujeres & Varones & Mujeres & Varones & Mujeres & \\
\hline Buenos Aires & 7359625 & 7810598 & 102113 & 99872 & 140274 & 106989 & 15619471 \\
\hline Catamarca & 137591 & 146234 & 31452 & 28185 & 13248 & 10990 & 367700 \\
\hline Chaco & 428677 & 456124 & 17154 & 16902 & 74190 & 62208 & 1055255 \\
\hline Chubut & 230562 & 234376 & 13418 & 12868 & 11018 & 7396 & 509638 \\
\hline Córdoba & 1415208 & 1533080 & 95793 & 95003 & 92686 & 74915 & 3306685 \\
\hline Corrientes & 395494 & 427448 & 17929 & 17841 & 72118 & 62427 & 993257 \\
\hline Entre Ríos & 511382 & 549831 & 30809 & 30151 & 63018 & 51959 & 1237150 \\
\hline Formosa & 211472 & 224455 & 9979 & 9438 & 41291 & 34288 & 530923 \\
\hline Jujuy & 285032 & 301669 & 21475 & 20990 & 23794 & 21390 & 674350 \\
\hline La Pampa & 130226 & 137482 & 17744 & 17496 & 9967 & 6411 & 319326 \\
\hline La Rioja & 141525 & 147082 & 15570 & 15160 & 8364 & 6628 & 334329 \\
\hline Mendoza & 666898 & 722121 & 29774 & 29328 & 149977 & 140272 & 1738370 \\
\hline Misiones & 394696 & 416963 & 27856 & 27252 & 124677 & 109865 & 1101309 \\
\hline Neuquén & 248076 & 256977 & 8669 & 8438 & 16485 & 12046 & 550691 \\
\hline Río Negro & 268191 & 280681 & 21011 & 19600 & 28164 & 21889 & 639536 \\
\hline Salta & 514081 & 543082 & 30121 & 29582 & 52393 & 44031 & 1213290 \\
\hline San Juan & 285803 & 306194 & 19634 & 18546 & 27256 & 22823 & 680256 \\
\hline San Luis & 185790 & 194949 & 14914 & 14431 & 12446 & 9195 & 431725 \\
\hline Santa Cruz & 130895 & 126942 & 4112 & 3292 & 4565 & 1042 & 270848 \\
\hline Santa Fe & 1392284 & 1501195 & 80316 & 80857 & 77188 & 65535 & 3197375 \\
\hline Sgo. del Estero & 288593 & 310087 & 35039 & 33975 & 108806 & 97154 & 873654 \\
\hline Tierra del Fuego & 60764 & 59337 & 420 & 292 & 3636 & 1871 & 126320 \\
\hline Tucumán & 562689 & 604072 & 21917 & 21781 & 123131 & 115044 & 1448634 \\
\hline CABA & 1330439 & 1561642 & 0 & 0 & 0 & 0 & 2892081 \\
\hline TOTAL & 17575993 & 18852621 & 667219 & 651280 & 1278692 & 1086368 & 40112173 \\
\hline
\end{tabular}

Fuente: Fuente: Elaboración propia a partir de datos del INDEC. Censo Nacional de Población, Hogares y Viviendas 2010, procesado con Redatam+SP 
ANEXO 2. Cantidad de hijos/as nacidos vivos/as de mujeres de 40 a 49 años total y porcentaje en las áreas urbanas, rural agrupada y rural dispersa según la información del Censo 2001 y Censo 2010

\begin{tabular}{|c|c|c|c|c|c|c|c|c|c|c|c|c|}
\hline \multirow{3}{*}{$\begin{array}{c}\text { Cant. } \\
\text { hijos/as } \\
\text { nacidos } \\
\text { vivos }\end{array}$} & \multicolumn{6}{|c|}{2001} & \multicolumn{6}{|c|}{2010} \\
\hline & \multicolumn{2}{|c|}{ Urbano } & \multicolumn{2}{|c|}{ R. Agrupado } & \multicolumn{2}{|c|}{ R. Disperso } & \multicolumn{2}{|c|}{ Urbano } & \multicolumn{2}{|c|}{ R. Agrupado } & \multicolumn{2}{|c|}{ R. Disperso } \\
\hline & Total & $\%$ & Total & $\%$ & Total & $\%$ & Total & $\%$ & Total & $\%$ & Total & \\
\hline 1 & 223743 & 12,8 & 5183 & 9,2 & 8465 & 8,1 & 278826 & 14,6 & 6126 & 9,8 & 8036 & 8,4 \\
\hline 2 & 509065 & 29,1 & 12507 & 22,1 & 17997 & 17,1 & 594032 & 31,2 & 14588 & 23,2 & 17921 & 18,9 \\
\hline 3 & 439961 & 25,2 & 12514 & 22,1 & 19775 & 18,8 & 458946 & 24,1 & 14519 & 23,2 & 19202 & 20,2 \\
\hline 4 & 249813 & 14,3 & 8446 & 14,9 & 15182 & 14,5 & 252218 & 13,2 & 9919 & 15,8 & 14943 & 15,7 \\
\hline 5 & 129033 & 7,3 & 5345 & 9,5 & 11044 & 10,5 & 129584 & 6,8 & 5820 & 9,3 & 9776 & 10,3 \\
\hline 6 & 72517 & 4,1 & 3757 & 6,6 & 8346 & 7,9 & 71075 & 3,7 & 3781 & 6,0 & 6721 & 7,1 \\
\hline 7 & 46441 & 2,6 & 2915 & 5,2 & 6916 & 6,6 & 49204 & 2,6 & 3084 & 4,9 & 6459 & 6,8 \\
\hline 8 & 29635 & 1,7 & 2023 & 3,6 & 5432 & 5,2 & 28401 & 1,5 & 1892 & 3,0 & 4266 & 4,5 \\
\hline 9 & 20623 & 1,1 & 1469 & 2,6 & 4121 & 3,9 & 17881 & 0,9 & 1305 & 2,1 & 2995 & 3,2 \\
\hline 10 & 11058 & 0,6 & 979 & 1,7 & 2966 & 2,8 & 10520 & 0,6 & 748 & 1,2 & 1981 & 2,1 \\
\hline 11 & 6017 & 0,3 & 587 & 1,0 & 1922 & 1,8 & 5551 & 0,3 & 408 & 0,6 & 1130 & 1,2 \\
\hline 12 & 4101 & 0,2 & 388 & 0,7 & 1400 & 1,3 & 3396 & 0,2 & 262 & 0,4 & 783 & 0,8 \\
\hline 13 & 1957 & 0,1 & 197 & 0,3 & 671 & 0,6 & 1632 & 0,1 & 139 & 0,2 & 435 & 0,5 \\
\hline 14 & 1149 & 0,1 & 121 & 0,2 & 409 & 0,4 & 903 & 0,1 & 84 & 0,1 & 183 & 0,2 \\
\hline 15 & 565 & 0,0 & 59 & 0,1 & 224 & 0,2 & 514 & 0,0 & 30 & 0,0 & 85 & 0,1 \\
\hline 16 & 326 & 0,0 & 33 & 0,1 & 125 & 0,1 & 255 & 0,0 & 13 & 0,0 & 51 & 0,1 \\
\hline
\end{tabular}

Fuente: Fuente: Elaboración propia a partir de datos del INDEC. Censo Nacional de Población, Hogares y Viviendas 2010, procesado con Redatam+SP 
ANEXO 3. Cantidad total y porcentaje de mujeres de 15 a 19 años que tienen hijos por lugar de residencia (urbano, rural agrupado y rural disperso) por provincia según la información de los Censos 2001 y 2010

\begin{tabular}{|c|c|c|c|c|c|c|c|c|c|c|c|c|}
\hline \multirow{3}{*}{ Provincias } & \multicolumn{6}{|c|}{2001} & \multicolumn{6}{|c|}{2010} \\
\hline & \multicolumn{2}{|c|}{ Urbano } & \multicolumn{2}{|c|}{ R. Agrupado } & \multicolumn{2}{|c|}{ R. Disperso } & \multicolumn{2}{|c|}{ Urbano } & \multicolumn{2}{|c|}{ R. Agrupado } & \multicolumn{2}{|c|}{ R. Disperso } \\
\hline & Total & $\%$ & Total & $\%$ & Total & $\%$ & Total & $\%$ & Total & $\%$ & Total & $\%$ \\
\hline Bs. Aires & 61719 & 11,0 & 1002 & 12,5 & 1553 & 15,2 & 80166 & 12,6 & 1044 & 13,0 & 1515 & 18,3 \\
\hline Catamarca & 1877 & 15,8 & 586 & 21,1 & 276 & 24,7 & 2011 & 14,1 & 484 & 17,1 & 229 & 22,7 \\
\hline Córdoba & 12325 & 10,5 & 1044 & 15,9 & 1195 & 17,8 & 13197 & 10,7 & 1135 & 13,7 & 1292 & 19,9 \\
\hline Corrientes & 5086 & 13,9 & 299 & 21,2 & 1365 & 19,4 & 5963 & 13,5 & 330 & 16,9 & 1245 & 19,5 \\
\hline Chaco & 7204 & 18,0 & 504 & 28,5 & 2151 & 28,5 & 8238 & 17,1 & 409 & 20,7 & 1681 & 25,8 \\
\hline Chubut & 2365 & 13,4 & 263 & 23,9 & 128 & 20,6 & 2627 & 12,8 & 220 & 18,7 & 78 & 15,3 \\
\hline Entre Ríos & 5953 & 13,6 & 419 & 16,6 & 977 & 16,8 & 6426 & 13,5 & 484 & 16,6 & 767 & 16,7 \\
\hline Formosa & 2979 & 15,3 & 176 & 21,9 & 1072 & 27,0 & 3433 & 13,8 & 222 & 20,3 & 936 & 25,3 \\
\hline Jujuy & 3390 & 12,5 & 396 & 20,9 & 618 & 25,1 & 3546 & 11,7 & 377 & 16,2 & 439 & 20,0 \\
\hline La Pampa & 1377 & 12,7 & 242 & 15,7 & 98 & 14,8 & 1562 & 13,2 & 196 & 13,7 & 67 & 17,8 \\
\hline La Rioja & 1618 & 14,3 & 245 & 17,6 & 160 & 21,3 & 2073 & 13,4 & 226 & 14,0 & 110 & 17,1 \\
\hline Mendoza & 5000 & 9,0 & 319 & 12,6 & 1818 & 14,6 & 6455 & 10,6 & 384 & 12,8 & 9167 & 11,7 \\
\hline Misiones & 5070 & 14,6 & 442 & 20,1 & 2777 & 23,4 & 6428 & 14,6 & 624 & 20,5 & 3168 & 25,6 \\
\hline Neuquén & 2639 & 13,0 & 167 & 19,5 & 309 & 21,6 & 3081 & 12,8 & 120 & 14,0 & 232 & 22,2 \\
\hline Río Negro & 2930 & 13,0 & 314 & 19,1 & 381 & 20,4 & 3095 & 12,7 & 339 & 17,4 & 356 & 18,1 \\
\hline Salta & 6641 & 14,5 & 728 & 23,4 & 1547 & 29,4 & 7754 & 13,7 & 660 & 20,4 & 1224 & 27,2 \\
\hline San Juan & 2509 & 10,4 & 198 & 13,6 & 451 & 16,8 & 3340 & 12,2 & 310 & 15,9 & 491 & 20,2 \\
\hline San Luis & 1940 & 13,9 & 182 & 16,8 & 148 & 19,5 & 2099 & 12,3 & 235 & 16,7 & 135 & 17,7 \\
\hline Santa Cruz & 1188 & 14,0 & 15 & 16,5 & 10 & 19,6 & 1625 & 14,5 & 31 & 14,0 & 16 & 24,6 \\
\hline Santa Fe & 14648 & 12,5 & 937 & 14,7 & 1632 & 22,4 & 17273 & 14,0 & 1012 & 14,2 & 1356 & 21,6 \\
\hline S. Estero & 4119 & 15,1 & 618 & 19,3 & 2125 & 23,7 & 4648 & 14,7 & 727 & 20,0 & 2358 & 24,2 \\
\hline Tucumán & 6151 & 12,5 & 340 & 15,9 & 1887 & 17,6 & 6555 & 11,7 & 358 & 15,1 & 2105 & 17,6 \\
\hline T. Fuego & 454 & 11,1 & 16 & 34,8 & 7 & 33,3 & 575 & 10,2 & 0 & 0,0 & 35 & 29,7 \\
\hline
\end{tabular}

Fuente: Fuente: Elaboración propia a partir de datos del INDEC. Censo Nacional de Población, Hogares y Viviendas 2010, procesado con Redatam+SP 
ANEXO 4. Tabla de la cantidad y porcentaje de población de 25 o más años por sexo según nivel educativo y área de residencia

\begin{tabular}{|c|c|c|c|c|c|c|}
\hline \multirow{2}{*}{$\begin{array}{c}\text { Área } \\
\text { de residencia }\end{array}$} & \multirow[t]{2}{*}{ Nivel educativo } & \multicolumn{3}{|c|}{ Cantidad de población } & \multicolumn{2}{|c|}{ Porcentaje } \\
\hline & & Varón & Mujer & Total & Varón & Mujer \\
\hline \multirow{10}{*}{ Urbano } & Inicial (jardín, preescolar) & 736.205 & 723.934 & 1.460 .139 & $4,55 \%$ & $4,15 \%$ \\
\hline & Primario & 6.191 .826 & 6.401 .272 & 12.593 .098 & $38,26 \%$ & $36,67 \%$ \\
\hline & $\mathrm{EGB}$ & 625.117 & 565.064 & 1.190 .181 & $3,86 \%$ & $3,24 \%$ \\
\hline & Secundario & 5.275 .438 & 5.276 .575 & 10.552 .013 & $32,60 \%$ & $30,23 \%$ \\
\hline & Polimodal & 605.263 & 640.990 & 1.246 .253 & $3,74 \%$ & $3,67 \%$ \\
\hline & Superior no universitario & 794.671 & 1.638 .844 & 2.433 .515 & $4,91 \%$ & $9,39 \%$ \\
\hline & Universitario & 1.748 .921 & 2.012 .912 & 3.761 .833 & $10,81 \%$ & $11,53 \%$ \\
\hline & Post universitario & 118.082 & 130.184 & 248.266 & $0,73 \%$ & $0,75 \%$ \\
\hline & Educación especial & 87.953 & 66.629 & 154.582 & $0,54 \%$ & $0,38 \%$ \\
\hline & Total & 16.183 .476 & 17.456 .404 & 33.639 .880 & $100 \%$ & $100 \%$ \\
\hline \multirow{10}{*}{$\begin{array}{c}\text { Rural } \\
\text { agrupado }\end{array}$} & Inicial (jardín, preescolar) & 26.772 & 25.979 & 52.751 & $4,43 \%$ & $4,41 \%$ \\
\hline & Primario & 332.980 & 300.207 & 633.187 & $55,11 \%$ & $50,93 \%$ \\
\hline & EGB & 34.493 & 30.188 & 64.681 & $5,71 \%$ & $5,12 \%$ \\
\hline & Secundario & 144.970 & 139.744 & 284.714 & $23,99 \%$ & $23,71 \%$ \\
\hline & Polimodal & 22.429 & 24.506 & 46.935 & $3,71 \%$ & $4,16 \%$ \\
\hline & Superior no universitario & 18.137 & 41.475 & 59.612 & $3,00 \%$ & $7,04 \%$ \\
\hline & Universitario & 20.889 & 24.471 & 45.360 & $3,46 \%$ & $4,15 \%$ \\
\hline & Post universitario & 1.075 & 1.141 & 2.216 & $0,18 \%$ & $0,19 \%$ \\
\hline & Educación especial & 2.505 & 1.787 & 4.292 & $0,41 \%$ & $0,30 \%$ \\
\hline & Total & 604.250 & 589.498 & 1.193 .748 & $100 \%$ & $100 \%$ \\
\hline \multirow{10}{*}{$\begin{array}{c}\text { Rural } \\
\text { disperso }\end{array}$} & Inicial (jardín, preescolar) & 46.264 & 44.405 & 90.669 & $4,13 \%$ & $4,72 \%$ \\
\hline & Primario & 752.482 & 587.619 & 1.340 .101 & $67,16 \%$ & $62,45 \%$ \\
\hline & EGB & 63.822 & 56.818 & 120.640 & $5,70 \%$ & $6,04 \%$ \\
\hline & Secundario & 177.976 & 155.055 & 333.031 & $15,88 \%$ & $16,48 \%$ \\
\hline & Polimodal & 30.815 & 33.570 & 64.385 & $2,75 \%$ & $3,57 \%$ \\
\hline & Superior no universitario & 18.027 & 35.045 & 53.072 & $1,61 \%$ & $3,72 \%$ \\
\hline & Universitario & 26.181 & 24.750 & 50.931 & $2,34 \%$ & $2,63 \%$ \\
\hline & Post universitario & 1.336 & 1.069 & 2.405 & $0,12 \%$ & $0,11 \%$ \\
\hline & Educación especial & 3.612 & 2.555 & 6.167 & $0,32 \%$ & $0,27 \%$ \\
\hline & Total & 1.120 .515 & 940.886 & 2.061 .401 & $100 \%$ & $100 \%$ \\
\hline \multirow{10}{*}{ Total } & Inicial (jardín, preescolar) & 809.241 & 794.318 & 1.603 .559 & $4,52 \%$ & $4,18 \%$ \\
\hline & Primario & 7.277 .288 & 7.289 .098 & 14.566 .386 & $40,64 \%$ & $38,39 \%$ \\
\hline & EGB & 723.432 & 652.070 & 1.375 .502 & $4,04 \%$ & $3,43 \%$ \\
\hline & Secundario & 5.598 .384 & 5.571 .374 & 11.169 .758 & $31,26 \%$ & $29,34 \%$ \\
\hline & Polimodal & 658.507 & 699.066 & 1.357 .573 & $3,68 \%$ & $3,68 \%$ \\
\hline & Superior no universitario & 830.835 & 1.715 .364 & 2.546 .199 & $4,64 \%$ & $9,03 \%$ \\
\hline & Universitario & 1.795 .991 & 2.062 .133 & 3.858 .124 & $10,03 \%$ & $10,86 \%$ \\
\hline & Post universitario & 120.493 & 132.394 & 252.887 & $0,67 \%$ & $0,70 \%$ \\
\hline & Educación especial & 94.070 & 70.971 & 165.041 & $0,53 \%$ & $0,37 \%$ \\
\hline & Total & 17.908 .241 & 18.986 .788 & 36.895 .029 & $100 \%$ & $100 \%$ \\
\hline
\end{tabular}

Fuente: Fuente: Elaboración propia a partir de datos del INDEC. Censo Nacional de Población, Hogares y Viviendas 2010, procesado con Redatam+SP 


\section{BIBLIOGRAFIA CITADA}

Alegre, S. (2015). Las nuevas generaciones de mujeres rurales como promotoras de cambio. Un estudio cuanti-cualitativo de la situación de las mujeres rurales jóvenes, de sus necesidades y oportunidades en Argentina. 1a ed ilustrada. Ministerio de Agricultura, Ganadería y Pesca de la Nación. MAGyP., Unidad para el Cambio Rural, UCAR. Ciudad Autónoma de Buenos Aires.

Alvarez G., Basco M., Biaggi M.C., Bruce, A., Cubiló, M.E., Díaz, M.E., Foti, P., Isa, M., Rueda, M.E. y Sanz, C. (1992). Trabajando con Mujeres Campesinas en el noroeste argentino. IICA, Buenos Aires.

Aradas, M.E. (2013). Desarrollo territorial: Desestructuración y reestructuración en las formas de producción y comercialización de los agricultores familiares. Aportes desde la perspectiva de género. Maestría en Gestión y Desarrollo Territorial. Facultad de Ciencias Econónicas y Estadísticas. Universidad Nacional de Rosario.

Artopoulos, A. (2020) ¿Cuántos estudiantes tienen acceso a Internet en su hogar en Argentina? Observatorio Argentinos por la Educación I. Recuperado de:

https://cms.argentinosporlaeducacion.org/media/reports/ArgxEdu Conectividad Coronavirus. $\underline{\mathrm{pdf}}$

Banco Mundial (2020). Banco Mundial BIRF - AlF. Datos. Recuperado de https://datos.bancomundial.org/indicador/SP.RUR.TOTL.ZS

Berdegué, J., \& Favareto, A. (2019). Desarrollo Territorial Rural en América Latina y el Caribe 2030. Alimentación, agricultura y desarrollo rural en América Latina y el Caribe. Santiago: FAO. http://www.fao.org/3/ca5059es/ca5059es.pdf

Biaggi, C. (1996). Los viajes de ida y vuelta: la migración en Santiago del Estero. Revista TRAVESSIA, revista do migrante. Publicación del CEM - Año IX, número 26. San Pablo.

Biaggi, C. (2008). Situación actual y políticas para la equidad de género en áreas rurales. En Schejtman, Alexander y Osvaldo Barsky (comps.) "El Desarrollo Rural en Argentina. Un enfoque territorial", Siglo XXI, Buenos Aires.

Biaggi, C., Canevari, C., \& Tasso, A. (2007). Mujeres que trabajan la tierra. Un estudio sobre las mujeres rurales en la Argentina. Proyecto de Desarrollo de Pequeños Productores Agropecuarios. Secretaría de Agricultura, Ganadería, Pesca y Alimentos, Buenos Aires (Argentina).

Biaggi, M. C. (2018). Análisis de la toma de decisiones en agriculturas familiares: la mecanización integral de la cosecha de la caña de azúcar en Tucumán (Tesis Doctoral, Facultad de Agronomía, Universidad de Buenos Aires).

http://ri.agro.uba.ar/files/download/tesis/doctorado/2019biaggimariacristina.pdf

Binstock, G. y Cerrutti, M. (2017). Escuelas técnicas. Características institucionales y desempeños. Informe Final. Serie de documentos de investigación 1. Centro de Estudios de Población (CENEP).

Blanco, H. y Ramirez, L. (2016). El sistema urbano primacial de la provincia de Formosa. Evolución poblacional de las principales urbes. Conference: XIV Encuentro de Profesores y Licenciados en Geografía de Formosa. Carrera de Geografía, Facultad de Humanidades, Universidad Nacional de Formosa. Formosa, 14 y 15 de octubre de 2016.DOI: 10.13140/RG.2.2.34780.90249

Buchbinder, N; McCallum, A. y Volman, V. (2019). El estado de la educación en la Argentina. Informe anual. Observatorio Argentinos por la Educación.

Craviotti, C. (2017). Dilemas en iniciativas de desarrollo orientadas a la agricultura familiar: Ios productores-elaboradores de quesos en Entre Ríos, Argentina. Revista de Ciencias Sociales, 30(41), 199-220. 
Crespo Pazos, M. (2015). Dinámica de las negociaciones y conflictos de asalariados citrícolas durante la última década en Tucumán, Argentina. Estudios del Trabajo. Revista de la Asociación Argentina de especialistas en estudios del trabajo (ASET), (50). Recuperado de https://aset.org.ar/ojs/revista/article/view/11

Díaz Langou, G., Cicciaro, J. y Zolotow, J. (2014). Piso de Protección Social en la Provincia de Chaco. Documento de trabajo № 127. Documento elaborado en el marco del proyecto conjunto CIPPECFundación Friedrich Ebert sobre los "Diálogos acerca del Piso de Protección Social en las provincias argentinas".

Dirección Nacional de Estadísticas y Censos (Sin fecha). Censo Nacional de Población 1960. Tomo 1. Total del País. Secretaría de Estado de Hacienda. Poder Ejecutivo Nacional. República Argentina.

EUROSTAT (2015). 5 October 2015: World Habitat Day Just over 40\% of the EU population lives in cities. Eurostat Press Office. Recuperado de https://ec.europa.eu/eurostat/documents/2995521/7020151/3-05102015-BPEN.pdf/bf18a8b3-998c-476d-b3af-58292b89939b

FAO (2015). Documento de Trabajo N 1. Características demográficas, económicas y sociales de la provincia del Neuquén. Proyecto FAO UTF ARG 017. Desarrollo Institucional para la Inversión. Recuperado de http://www.fao.org/fileadmin/user upload/rlc/utf017arg/neuquen/DT 01 Caracter\%C3\%ADsti cas demogr\%C3\%A1ficas econ\%C3\%B3micas y sociales.pdf

Ferro, S. L. (2013). Género y Propiedad rural. Catamarca, Santiago del Estero y Tucumán. Unidad para el Cambio Rural. Ministerio de Agricultura, Ganadería y Pesca de la Nación Argentina.

Frenkel, J. (2019). El embarazo adolescente en la Argentina. CECE.

Gogna, M. y Binstock, G. (2017). Anticoncepción y maternidad: Hallazgos de un estudio cuanticualitativo con adolescentes de 18 y 19 años de cuatro provincias argentinas. Salud colectiva, 13, 63-72.

González, D., Mamanis, S., Prudant, E., y Scarfó, G. (2015). Panorama de la Educación Rural en Argentina. Boletín Temas de Educación, 12(15), 3-48.

Gutiérrez, T. (2017) Educación, agro y sociedad: políticas educativas agrarias en la región pampeana, 1897-1955. - 1a ed. - Bernal: Universidad Nacional de Quilmes. Libro digital, EPUB (Convergencia).

Instituto Nacional de Estadística y Censos (1973). Censo Nacional de Población, Familias y Vivienda de 1970. Buenos Aires.

Instituto Nacional de Estadística y Censos (1983). Censo Nacional de Población y Vivienda 1980. Serie D. Población. Buenos Aires

Instituto Nacional de Estadística y Censos (1992). Censo Nacional de Población y Vivienda 1991. Buenos Aires.

Instituto Nacional de Estadística y Censos (2001). Censo Nacional de Población, Hogares y Viviendas. Buenos Aires.

Instituto Nacional de Estadística y Censos (2013). Estimaciones y proyecciones de población 2010 2040: total del país. - 1a ed. Ciudad Autónoma de Buenos Aires.

Instituto Nacional de Estadística y Censos (2015). Población e inclusión social en la Argentina del Bicentenario: Indicadores demográficos y sociales. 1a ed. Ciudad Autónoma de Buenos Aires. Libro digital, PDF. 
Instituto Nacional de Estadística y Censos (2019). Censo Nacional Agropecuario 2018: resultados preliminares. - 1a ed. - Libro digital, PDF. Ciudad Autónoma de Buenos Aires.

Instituto Nacional de Estadísticas y Censos (2012). Censo Nacional de Población, Hogares y Viviendas 2010. Censo del Bicentenario. Resultados definitivos, Serie B N.o 2. Tomo 1. Buenos Aires

Instituto Nacional de Estadísticas y Censos (2021). Censo Nacional de Población, Hogares y Viviendas 2010. Recuperado de https://www.indec.gob.ar/indec/web/Nivel4-CensoNacional-3999-Censo-2010

Instituto Nacional de Estadísticas y Censos. (2021). Censo 2001.

https://www.indec.gob.ar/indec/web/Nivel4-Tema-2-41-134

Instituto Nacional de Estadísticas y Censos. (2021). Glosario. Recuperado de https://www.indec.gob.ar/indec/web/Institucional-Indec-Glosario

Instituto Nacional de Estadísticas y Censos. (2021). Indicadores de salud. Recuperado de https://www.indec.gob.ar/indec/web/Nivel4-Tema-4-32-94

Instituto Nacional de Estadísticas y Censos. (2021). Indicadores demográficos de la Argentina. Recuperado https://www.indec.gob.ar/indec/web/Institucional-Indec-IndicadoresDemograficos

Kabeer, N. (1994). Reversed Realities: Gender hierarchies in development thought. Londres: Ed. Verso.

Klarik, M. F. (2019). Agronegocios, pueblos indígenas y procesos migratorios rururbanos en la provincia de Salta, Argentina. Revista Colombiana de Antropología, 55(2), 65-92.

Linardelli, M.F. (2019). Sostener la vida. Experiencias de salud, enfermedad y cuidados de mujeres migrantes que trabajan en el agro de Mendoza (Tesis Doctoral, Facultad de Ciencias Políticas y Sociales, Universidad Nacional de Cuyo).

Ministerio de Agricultura, Ganadería y Pesca (2021). La conectividad en el medio rural. https://www.magyp.gob.ar/sitio/areas/cambio rural/boletin/conectividad.php

Olea, M. (2013). Ruralidad y educación en Argentina: instituciones, políticas y programas.

Recuperado de

http://www.oppad.uns.edu.ar/docs/trabajos/congresos/ruralidad\%20y\%20educacion.pdf

Olmos, A. E. y Pallarino, L. (2019). Gestionar la mejora de la educación rural en un país federal. Planificación, financiamiento y administración de un programa socioeducativo en la República Argentina. Estudios rurales, 9(17), 198-230.

Otero, H. (1998). Estadística censal y construcción de la Nación. El caso argentino, 1869-1914. Boletín del Instituto de Historia Argentina y Americana "Dr. Emilio Ravignani”, 16(17), 123-149.

Palamidessi, M (2003). La oferta de educación secundaria para adolescentes y jóvenes en contexto rural en el NEA y NOA, en: Bruniard, R. (coord.) Educación, desarrollo rural y Juventud. Buenos, Aires, IIPE-OEI.

Pantelides, E. A. (1989). La fecundidad argentina desde mediados del siglo XX (No. 41). CENEP.

Peretti, G., Castelnuovo, J., Demarchi, M., Gómez, N. J., \& Varisco, M. (2019). Redistribución de la población en el sistema de asentamientos urbanos de Argentina entre 1980 y 2010. In XXI Jornadas de Geografía de la UNLP (La Plata, 9 al 11 de octubre de 2019).

Programa Nacional de Salud Integral en la Adolescencia (2018). Niñas y adolescentes menores de 15 años embarazadas. Resumen Ejecutivo. Ministerio de Salud.

Schejtman, A., \& Berdegué, J. (2004). Desarrollo territorial rural. Debates y temas rurales, 1, 746. 
Sobre la Educación, F. M. (2000). Marco de acción de Dakar. Francia: UNESCO. Recuperado de https://unesdoc.unesco.org/ark:/48223/pf0000121147 spa

UNESCO (1991). Anuario Estadístico 1991.

http://www3.eurosur.org/FLACSO/mujeres/argentina/educ-1.htm

Vallejos, V.H., Acosta Felquer, A., Botana, M. I., Coppiarolo, L., Díaz, M., Pereira Sandoval, M. y Pohl Schnake, V. (2016). Una mirada al corazón de Corrientes: tensiones territoriales en torno a los bienes comunes en el Iberá. IE Libro de la Junta de Geografía de la Provincia de Corrientes (pp. 59-82).

Vicién, J. (1951). Distribución de la población en la República Argentina, 1869-1947. (Tesis de Doctorado. Universidad de Buenos Aires.) Recuperado de http://bibliotecadigital.econ.uba.ar/download/tesis/1501-0551 VicienJ.pdf 